\title{
Nuclear Waste Management Decision-Making Support with MCDA
}

\author{
A. Schwenk-Ferrero ${ }^{1}$ and A. Andrianov ${ }^{2}$ \\ ${ }^{1}$ Karlsruhe Institute of Technology (KIT), Hermann-von-Helmholtz-Platz 1, 76344 Eggenstein-Leopoldshafen, Germany \\ ${ }^{2}$ National Research Nuclear University MEPhI (Moscow Engineering Physics Institute), Kashirskoe Shosse 31, Moscow 115409, Russia
}

Correspondence should be addressed to A. Schwenk-Ferrero; aleksandra.schwenk-ferrero@kit.edu

Received 2 February 2017; Revised 5 May 2017; Accepted 31 May 2017; Published 25 July 2017

Academic Editor: Luca Podofillini

Copyright (C) 2017 A. Schwenk-Ferrero and A. Andrianov. This is an open access article distributed under the Creative Commons Attribution License, which permits unrestricted use, distribution, and reproduction in any medium, provided the original work is properly cited.

\begin{abstract}
The paper proposes a multicriteria decision analysis (MCDA) framework for a comparative evaluation of nuclear waste management strategies taking into account different local perspectives (expert and stakeholder opinions). Of note, a novel approach is taken using a multiple-criteria formulation that is methodologically adapted to tackle various conflicting criteria and a large number of expert/stakeholder groups involved in the decision-making process. The purpose is to develop a framework and to show its application to qualitative comparison and ranking of options in a hypothetical case of three waste management alternatives: interim storage at and/or away from the reactor site for the next 100 years, interim decay storage followed in midterm by disposal in a national repository, and disposal in a multinational repository. Additionally, major aspects of a decision-making aid are identified and discussed in separate paper sections dedicated to application context, decision supporting process, in particular problem structuring, objective hierarchy, performance evaluation modeling, sensitivity/robustness analyses, and interpretation of results (practical impact). The aim of the paper is to demonstrate the application of the MCDA framework developed to a generic hypothetical case and indicate how MCDA could support a decision on nuclear waste management policies in a "small" newcomer country embarking on nuclear technology in the future.
\end{abstract}

\section{Application Context}

From a formal point of view, the decision problem formulation is a triplet consisting of (1) a set of potential alternatives which describe the possible actions that a decision-maker can undertake, (2) a set of points of view under which the potential actions are analyzed, evaluated, and compared, including different scenarios for the future, and (3) the problem statement. This section describes the problem application context.

It should be noted that assessment of the technical performance and safety of repository sites is a very complex $\mathrm{R} \& \mathrm{D}$ problem. Therefore, the technical aspects of "repository" options will be only reviewed and briefly discussed within the confines of the paper. General criteria and metrics (indicators) which are in this case rather dynamic (time frame-dependent), are, however, addressed.
In practice, the extent of $\mathrm{R} \& \mathrm{D}$ efforts is dependent on specific national conditions, for instance, available geological formations (rock medium) for final HLW disposal in a country and appropriate assessment of characteristics of nuclear waste that is necessary for designing a HLW repository. Thus the technology-holding countries have already established expert organizations responsible for final high-level waste disposal and conducting R\&D activities on safety assessment studies, on minimization of the impact on the environment, and on site robustness tests (predictable performance response in the face of uncertainties).

In order to construct an objective hierarchy tree, IAEA basic principles are therefore used. These principles for nuclear waste management strategy choice are subdivided into three main categories: beneficial, responsible, and sustainable use. The presented framework can incorporate opinions and judgements of relevant stakeholders like technical 
experts, local authorities, neighboring countries, and national or international environmental groups.

1.1. Introduction. Nuclear power plants operate in 31 countries around the world. According to today's estimates, over 45 further countries consider embarking upon nuclear power programs in the future. The experience from commercial use of nuclear energy gained over nearly six past decades has stimulated the implementation of many different nuclear fuel cycles (NFC). Currently, industrially implemented nuclear technologies are mainly based on an open and a partly closed NFC, the latter recycling plutonium once [1]. All NFC types, including the advanced closed NFC with multiple recycling of fissionable materials, have in common that both the front- and the back-end fuel production stages generate the radioactive waste. Nevertheless, nuclear power production is the only large-scale energy-generating technology which assumes full responsibility for all its waste forms with the provision made for including a priori the waste management costs into the total final electricity price. Moreover, there are mature proven technologies which, if implemented at each stage of NFC, are able to safeguard the safe high-, intermediate-, and low-level waste disposal [2].

In each country, management of radioactive waste (as of any other industrial waste) is subject to the general legal framework. Practice shows that the majority of nuclear power-holding countries first accumulates the inventory of high-level wastes (HLW) that cannot be accepted directly in near-surface or subsurface disposal facilities to dispose them later, in the mid or long term, in a deep geological repository for safe enclosure. This strategy, although technically feasible and permitting a complete waste isolation from the biosphere in the future, imposes considerable economic burden. Countries with small- and medium-size nuclear programs may miss the full-range expertise and necessary financial resources to launch their own deep geological repository programs. Still, other countries may be interested in a strategy for waste management based on settlement of a multinational or regional repository and may be ready to share costs and benefits within a common program [3]. For instance, in Europe, a pilot initiative SAPIERR (Support Action: Pilot Initiative for European Regional Repositories) has been launched with a future objective to establish a proper legal and regulatory framework for international radioactive waste management [4]. The SAPIERR framework is based on recommendations contained in the IAEA Safety Standards documents.

Some newcomer countries, which do not operate nuclear power plants yet but consider the future use of nuclear power generation, may be interested in other spent nuclear fuel (SNF) management option which foresees returning the SNF after a suitable cooling time in decay storages (intermediate storage) to the technology holder and fuel supplier host country which has an expertise and the facilities for necessary further HLW management that can be either reprocessing or final disposal.

There is a general consensus among countries running nuclear programs that the back end of any NFC (a closed one, too) requires installations like geological disposal and/or facilities with interim storage capacity even when a different alternative to a national repository is pursued for back-end waste management. To date, a greatest unity of regulatory approaches has been achieved in the area of radioactive transport on the solid basis of mature and well-tested international transport regulations of the IAEA. The fast international progress in this area could provide a sample for inspection in the area of multinational geological disposal regulations.

The safe implementation of deep geological repositories is a long-time effort which can be first accomplished after many decades of R\&D on techniques implemented to design, construct, operate, and license the repository site and the decommissioning of other fuel storage installations. Meanwhile, the availability of adequate national interim storage capacities and perseverative licensing regulations may be required. However, such strategic delays may be attractive for three reasons:

(1) Natural decrease of radioactivity and of the heat load of HLW occurring after the short-lived fission products contained in waste bulk have decayed, making the SNF handling and disposal much simpler

(2) Public acceptance, increasing the level of societal confidence, which might be a key issue in some countries and might be achieved while allowing citizens to participate in the decision-making process

(3) Economic issues, elongated time to implement various cost-share allocation models.

International organizations such as IAEA and the European Community have been supporting R\&D programs on technical, economic, and institutional aspects of regional SNF facilities. The multinational repository still requires plenty of specific legal and contractual frameworks that must be clarified and regulated in bilateral or contractual/treaties within internationally oriented frameworks.

\subsection{Review of Accumulated SNF Inventories and Challenges} and Opportunities in Nuclear Waste Management. In principle, the volume of nuclear wastes produced by nuclear installations is very small compared to wastes from other large-scale energy-generating technologies. It contains, however, similar to other technologies (e.g., coal and oil) hazardous material [5]. Annually, ca. $200,000 \mathrm{~m}^{3}$ of low- and intermediate-level radioactive wastes (LLW or ILW, resp.) and ca. $10,000 \mathrm{~m}^{3}$ or 12,000 tonnes of HLW (including SNF declared as waste) are produced worldwide [6]. SNF discharged from NPPs may be stored "wet" in water pools or basins or "dry" in various configurations including nonsealed or sealed containers until retrieved for final disposal. Safe storage requires avoiding degradation to the fuel that would impact functions related to safety.

Usually, SNF from NPPs is stored in ponds at reactor or reactor complex sites. After suitable (fuel type-dependent) cooling time, SNF assemblies can be either sent to be reprocessed in reprocessing plants or safely packed in dry storage casks and transferred into decentralized or centralized interim storages. In the latter case, after subsequent decay 
TABLE 1: SNF-produced and cumulative inventory in storage in 2016, 2020, and 2030 [6].

\begin{tabular}{|c|c|c|c|c|c|c|}
\hline \multirow{2}{*}{ Country } & \multicolumn{2}{|c|}{2016} & \multicolumn{2}{|c|}{2020} & \multicolumn{2}{|c|}{2030} \\
\hline & Arising* & In storage $e^{* *}$ & Arising* & In storage ${ }^{* *}$ & Arising* & In storage $e^{* *}$ \\
\hline OECD America & 3,702 & 130,437 & 4,013 & 141,222 & 3,208 & 165,537 \\
\hline Canada & 1,591 & 52,528 & 1,535 & 54,063 & 1,065 & 56,092 \\
\hline Mexico & 24 & 685 & 49 & 857 & 24 & 1,176 \\
\hline United States & 2,087 & 77,224 & 2,429 & 86,302 & 2,119 & 108,269 \\
\hline OECD Europe & 7,404 & 260,874 & 8,026 & 282,444 & 6,416 & 331,074 \\
\hline Belgium & $-19^{(2015)}$ & $3,456^{(2015)}$ & N/A & N/A & N/A & N/A \\
\hline Czech Republic & 75 & 1,926 & 80 & 2,242 & 81 & 3,056 \\
\hline Finland & 55 & 2,104 & 90 & 2,362 & 131 & 3,289 \\
\hline France & 300 & 15,700 & 300 & 16,900 & N/A & N/A \\
\hline Germany & 150 & 8,884 & 127 & 9,751 & 0 & 10,477 \\
\hline Hungary & 36 & 1,240 & 39 & 1,396 & 84 & 2,031 \\
\hline Italy & 0 & $1.68^{(\mathrm{a})}$ & 0 & $1.68^{(\mathrm{b})}$ & 0 & 0 \\
\hline Netherlands & 8 & 601 & 8 & 633 & 8 & 700 \\
\hline Slovak Republic & 36 & 1,578 & 58 & 1,757 & 55 & 2,308 \\
\hline Slovenia & 15 & 470 & 15 & 513 & 15 & 666 \\
\hline Spain & 138 & 4,979 & 108 & 5,532 & 0 & 6,678 \\
\hline Sweden & $143^{(2015)}$ & $6,049^{(2015)}$ & N/A & N/A & N/A & $\mathrm{N} / \mathrm{A}$ \\
\hline Switzerland & 53 & 1,404 & 48 & 1,604 & 45 & 2,057 \\
\hline United Kingdom $^{(c)}$ & 717 & 3,955 & 25 & 2,826 & 25 & 5,848 \\
\hline OECD Pacific & 1,707 & 52,346 & & & & \\
\hline Japan & $380^{(2015)}$ & $14800^{(2015)}$ & N/A & N/A & N/A & N/A \\
\hline Korea ${ }^{(d)}$ & 803 & 15,579 & 901 & 19,120 & 596 & 27,380 \\
\hline OECD & 1,183 & 30,379 & & & & \\
\hline Russia & 650 & 21,980 & 716 & 23,540 & 845 & 26,724 \\
\hline NEA & 1,833 & 52,359 & & & & \\
\hline
\end{tabular}

(a) Part of 234.9 tHM (before irradiation) transported to reprocessing facility and 1.68 tHM (after irradiation) waiting for dry storage; ${ }^{(\mathrm{b})} 1.68$ tHM transported to LLW national repository for temporary storage awaiting geological disposal; ${ }^{(c)}$ cumulative in-storage totals include fuel arising from a steam-generating heavy water reactor, the prototype fast breeder reactor, and breeder fuel from the Dounreay fast reactor; ${ }^{(d)}$ including LWR fuel and HWR fuel; ${ }^{*}$ tHM/year; ${ }^{* *}$ tHM cumulative; N/A: not available.

storage period (between 40 and 50 years), the SNF subassemblies are ready for encapsulation or loading into dedicated casks for emplacement in a permanent deep repository.

The reprocessing of SNF is a waste management option which relies on the separation of fissile material (usually $\mathrm{U}$ and $\mathrm{Pu}$ isotopes) from SNF and recycling it as fresh fuel component by reloading into nuclear power plants. HLW being mostly fission products and minor actinides are vitrified during reprocessing into borosilicate (Pyrex) glass, sealed into heavy stainless-steel cylinders about $1.3 \mathrm{~m}$ high, and temporarily stored for eventual final disposal in deep underground. The hulls and end-fittings of the reprocessed fuel are compacted in order to reduce their volume and usually are incorporated into cement and disposed as ILW.

The SNF inventory of reactor-type facilities like power reactors, research reactors, and critical assemblies and of the bulk-handling front-end conversion plants, enrichment plants, fuel fabrication plants, and back-end reprocessing plants, separate storage facilities, and other facilities is nationally and internationally safeguarded. For instance, NEA OECD publishes yearly SNF arising and cumulative inventory in storages placed at NEA and OECD member countries.

The inventories of SNF in tonnes of heavy metal (tHM) produced and the cumulative inventory stored in the reference year 2016 (in all but three NEA member countries) and in 2015 (in Sweden, Japan, and Belgium) in NEA member countries can be seen in Table 1 [6]. This table contains also prognosticated future inventories for 2020 and 2030, respectively. Future nuclear technology users can find information on the approaches and criteria that should be considered for the selection of away-from-reactor type SNF storage facilities in many technical documents issued by IAEA (e.g., [17]). A Guidebook on Spent Fuel Storage (IAEA Technical Series Report) [18] discusses factors to be considered in the evaluation of SNF storage options.

Challenges and opportunities of fuel waste management options while using open and/or fully closed NFC are compared in Table 2 [7]. Key decisions required during implementation of nuclear energy programs including waste management strategies are schematically depicted in Figure 1 [7]. Moreover, Figure 1 delineates consequences of 
TABLE 2: Challenges and opportunities associated with the open and the closed NFC and nuclear waste management options [7].

\begin{tabular}{|c|c|c|}
\hline Aspect & Open NFC & Fully closed NFC \\
\hline $\begin{array}{l}\text { Uranium } \\
\text { consumption }\end{array}$ & $\begin{array}{l}-20 \text { tonnes U/TWh (i.e., } 100 \text { to } 200 \text { tonnes of uranium } \\
\text { per year of reactor operation) }\end{array}$ & +Consumption reduced by a factor of 50 to 100 \\
\hline $\begin{array}{l}\text { Complexity of the } \\
\text { techniques }\end{array}$ & $\begin{array}{l}+ \text { Few technically relatively simple management and } \\
\text { handling steps }\end{array}$ & $\begin{array}{l}\text {-Complexity increased by use of reprocessing and fast } \\
\text { neutron reactor system }\end{array}$ \\
\hline $\begin{array}{l}\text { Maturity of the } \\
\text { techniques, } \\
\text { developments } \\
\text { required }\end{array}$ & $\begin{array}{l}\text { +Long experience with interim storage } \\
\text {-Encapsulation and disposal in the design and } \\
\text { licensing phase }\end{array}$ & $\begin{array}{l}\text { - Limited experience with operation of fast neutron } \\
\text { reactors, new reactors in design phase } \\
\text {-Developments for the SNF partitioning and } \\
\text { transmutation techniques }\end{array}$ \\
\hline Waste disposal & $\begin{array}{l}\text { - Large repository footprint (due to waste volume and } \\
\text { heat release) } \\
\text {-Very long timescale to reach radiotoxicity of natural } \\
\text { uranium (200,000 years) }\end{array}$ & $\begin{array}{l}\text { +Reduction for the footprint by a factor of } 1 / 3 \text { (due to } \\
\text { reduced volume and heat release for high level waste) } \\
+ \text { If partitioning and transmutation is applied: } \\
\text { significant reduction of the timescale to reach } \\
\text { radiotoxicity of natural uranium (theoretically less than } \\
1000 \text { years) }\end{array}$ \\
\hline Safety & $\begin{array}{l}\text { +Fewer handling steps } \\
\text {-More complicated long-term safety }\end{array}$ & $\begin{array}{l}\text {-More operations and transport } \\
+ \text { Potential for simpler long-term safety }\end{array}$ \\
\hline Security & $\begin{array}{l}\text { +Fewer handling steps } \\
+ \text { No separated sensitive (fissile) material }\end{array}$ & $\begin{array}{l}\text {-More operations and transport } \\
\text {-Sensitive material separated }\end{array}$ \\
\hline Proliferation & $\begin{array}{l}+ \text { No free sensitive material } \\
\text {-Long-term safeguards of the repository }\end{array}$ & $\begin{array}{l}\text { +Less or no enrichment needs } \\
\text {-Significant amount of sensitive material separated in } \\
\text { the processes } \\
\text { +No sensitive material in repository }\end{array}$ \\
\hline
\end{tabular}

each particular decision. General technical, economic, and institutional aspects of regional SNF storage facilities and the framework for their implementation are addressed in detail in [8]. This document indicates that three categories of stakeholders are going to be involved in a regional SNF storage system: (1) the hosting country offering the regional SNF storage services (away-from-reactor); (2) a group of customer countries interested in transferring their SNF to the hosting country; (3) a group of third-country parties having interest in the storage system. The incentives of each group can have technical, economic, financial, political, or institutional nature. Third-party countries could have specific interests with regard to the future SNF storage demands or because some countries share the borders with host and customers and may be asked to allow the SNF transportation across their country. Options of regional storage services, which can be offered to customers, are shown in Figure 2 [8].

\subsection{Review of Framework for Implementation of National and} International SNF Storage Facilities. The general framework for implementation of national and international SNF storage facilities encompasses different technologies and associated safety aspects for storage of research and power reactor fuel, the preparation of fuel for transport and storage, the acceptance criteria for the reception of fuel subassemblies, and the envisaged storage time. Additionally environmental, institutional, and ethical issues play a role as well as political feasibility and the overall benefits and risks connected to the particular implementation process. The regional cooperation and approaches may provide attractive and challenging prospects for member states from the economic, safety, environmental, and security points of view. New challenges that involved countries may be confronted with are as follows [19]:

(1) Technical requirements: safety criteria and standards, safeguards and physical protection, fuel acceptance criteria, long-term stability of systems and stored fuel, selection of site, infrastructure aspects, storage technology, licensing, operations, transport, decommissioning, and $\mathrm{R} \& \mathrm{D}$

(2) Economic considerations: financial sources and conditions, economic evaluation, potential host countries, and customers

(3) Institutional considerations: organization and legal aspects

(4) Political and public acceptance considerations.

Thus, trading-off between potential benefits and risks has to be made in all facets of the project analyses (see [8] for further details):

(1) Technical benefit might be a possibility to implement a proven technology, to share the experience, a transfer of technology, an optimization of design, enhancement of quality and safety aspects, minimization of the number of storage facilities, and global radiological risk and environmental impacts, enhanced security against sabotage or terroristic attacks due to more robust security measures, and a central location when compared to decentralized, widely spread storage installations.

(2) Economic benefits can arise from shared efforts, for instance, the transfer of funds from customer to 


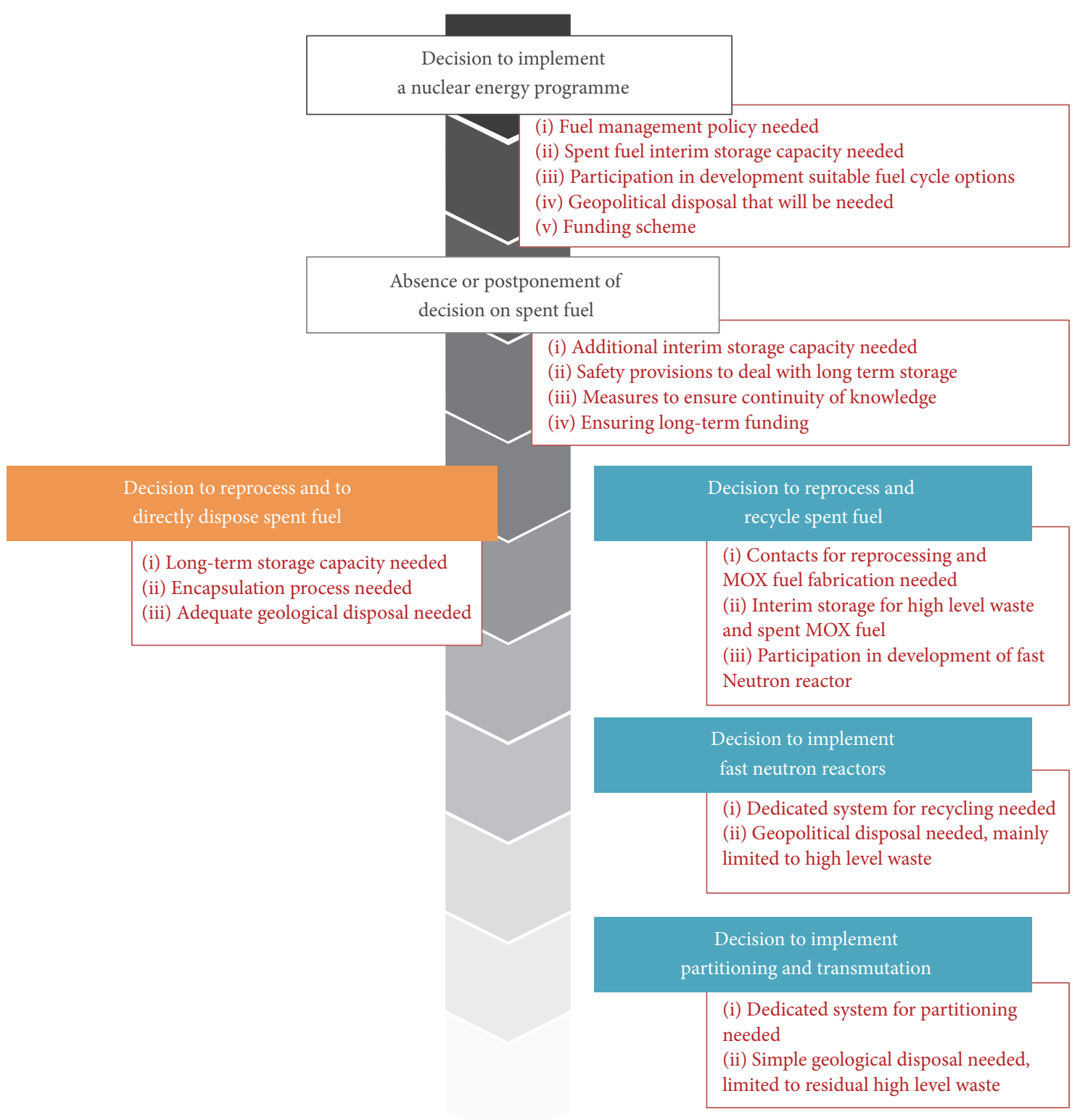

FIGURE 1: Key decisions and main consequences with respect to SNF as given in [7].

host country and the profit of the operation facility. Important economic benefits to the community hosting the facility can be obtained from local taxes, employment opportunities, and development of local infrastructure.

(3) Institutional benefits might be creation of an international framework, strengthening the will of seeking solutions supporting global challenges, demonstration of the feasibility of international treaties and conventions, and so on.

(4) Social benefits may include relevant environmental and social programs in terms of infrastructure and economic incentives at the site.

(5) Technical risks are similar in national and multinational storage programs, but the implementation of a regional repository is likely to result in increased long-distance transportation across the neighboring countries.

(6) Institutional risk is associated with the operation time of SNF storage facilities, which is much longer than the existence of any government or institution, and intergenerational data protection management with respect to SNF characteristics, for instance, a burn-up history which might be important in case of the future SNF handling and repackaging.

\subsection{Survey of Safety and Performance Criteria for Geological} Repositories. HLW repositories should (1) cause no significant long-term hazard to human health and (2) pose no unacceptable harm to the environment. Repository safety 


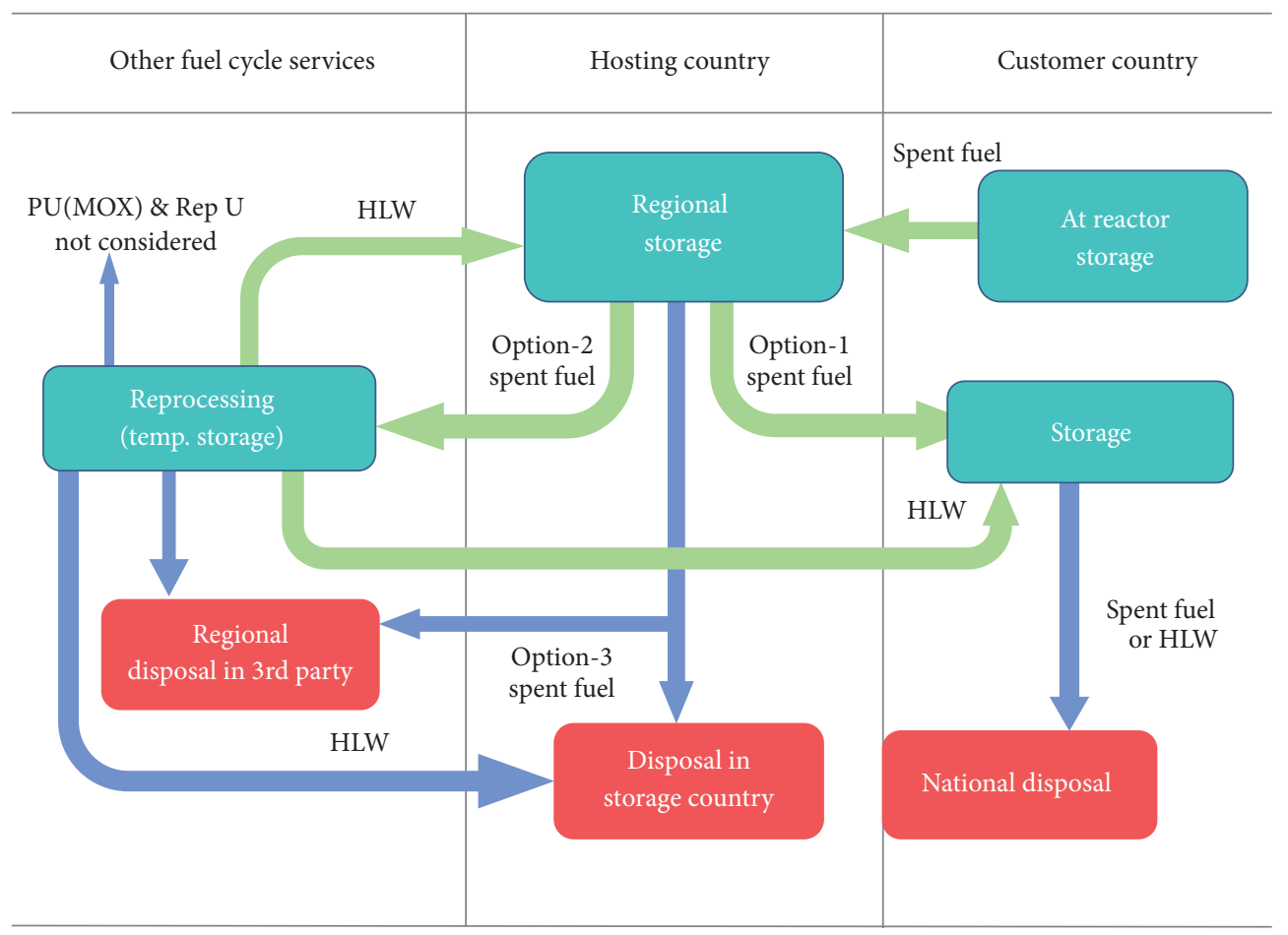

Direct regional storage link

Indirect regional storage link

FIGURE 2: A regional SNF storage system and possible service options derived from [8].

indicators are numerical measures quantifying the potential hazards or harm of a disposal system. To evaluate the safety indicators extensive safety case studies over different time frames are required. The role and utility of different types of safety indicators have been discussed in IAEA publication [9]. The main conclusions are summarized in Table 3.

The long-term safety of disposal systems is measured by means of radiological dose and risk indicators typically evaluated while assessing a level of safety provided by the repository in the safety case studies. The dose indicator assesses the effective dose rate to humans assumed to be exposed to radionuclides which might migrate from the disposal systems. The risk analysis takes into account the scenario likelihood leading to exposure and transforms the dose to a corresponding risk level using suitable dose/risk conversion factors [9].

In general, a safety case should bring in evidence and provide reasonable assurance that the repository will be safe; that is, the eventual consequences of any migration of radionuclides to the accessible environment are in compliance with the dose and risk standards that are acceptable today [9]. A safety case is usually compiled at different stages of the stepwise repository development programme to inform the authorities about both the adequacy of the design with respect to containment, isolation, and multiple barriers and the adequacy of the safety assessment. The multiple barrier concepts are of particular importance because the long-lived waste containment features degrade over time. Furthermore, the retardation of materials migrating from the waste form and engineer barriers of the disposal facility and through the surrounding geosphere are important elements of repository safety.

To achieve safety disposal the waste must be isolated from the accessible environment. Depth and disposal facility integrity play therefore an important role, together with site selection in an area unlikely to be affected by inadvertent human intrusion or natural events over the time frames of concern. To ensure the adequacy and diversity of the containment and isolation functions a range of indicators must be estimated that favour robustness and minimize uncertainty.

The IAEA publication [9] pointed to problems associated with the use of dose and risk as measures of safety, particularly in the far future. The difficulties are mainly related to the uncertainty surrounding the evaluation, to provide direct evidence of assurance, and to public communication. The IAEA paper concludes that a safety case assessment can be made most effectively by the combined use of several safety indicators, including not only dose and risk, but also environmental fluxes and the concentrations at the timescales relevant to radiochemical processes. However it was recognized that dose and risk remain the most fundamental indicators of safety.

In the European SPIN (Safety and Performance Indicators) project, twenty-one safety and performance indicators for assessing the long-term performance of geological repositories were tested [20]. These indicators are complementary to radiation doses to humans. Besides providing alternative 
TABLE 3: Safety indicators survey [9].

\begin{tabular}{|c|c|c|}
\hline Indicator & Advantages & Disadvantages \\
\hline \multicolumn{3}{|c|}{ Humans } \\
\hline Risk & $\begin{array}{l}\text { Direct indicator of impact on humans } \\
\text { Can take likelihood of the exposure into account } \\
\text { Enables direct comparison with other hazards }\end{array}$ & $\begin{array}{l}\text { Possible communication problems } \\
\text { Problem in estimating probability } \\
\text { Problems of applicability in far future } \\
\text { Calculational complexity }\end{array}$ \\
\hline Dose & $\begin{array}{c}\text { Well established and understood } \\
\text { Direct indicator of impact on humans } \\
\text { Integrates all exposure roots to humans }\end{array}$ & $\begin{array}{l}\text { Does do not take likelihood of exposure into account } \\
\text { Problems of applicability in the far future }\end{array}$ \\
\hline \multicolumn{3}{|c|}{ Environment } \\
\hline $\begin{array}{l}\text { Environmental } \\
\text { concentration }\end{array}$ & $\begin{array}{c}\text { Conceptually simple } \\
\text { Independent of human status } \\
\text { Measure of local environmental impact }\end{array}$ & $\begin{array}{l}\text { No direct natural comparators for artificial nuclides } \\
\text { Problems in defining a generic reference level }\end{array}$ \\
\hline Biospheric flux & $\begin{array}{l}\text { Relatively independent of local biosphere and human } \\
\text { changes }\end{array}$ & $\begin{array}{c}\text { Conceptually difficult } \\
\text { Problems in defining a generic reference level } \\
\text { No direct natural comparators for artificial nuclides } \\
\text { Not a local safety indicator }\end{array}$ \\
\hline $\begin{array}{l}\text { Flux through } \\
\text { barriers }\end{array}$ & Direct indicator of barrier performance & $\begin{array}{c}\text { May not be directly related to safety } \\
\text { Could divert attention from overall safety objectives }\end{array}$ \\
\hline Time & $\begin{array}{c}\text { Easy to understand } \\
\text { Direct indicator of barrier performance }\end{array}$ & May not be directly related to safety \\
\hline \multicolumn{3}{|c|}{ Waste } \\
\hline Radiotoxicity & $\begin{array}{c}\text { Conceptually simple } \\
\text { Indicator of time periods of concerns }\end{array}$ & Incomplete and sensitive to assumptions \\
\hline
\end{tabular}

ways to evaluating the safety of future geological repositories, these indicators help to understand how the repositories work by addressing the facility global performance and the performance of each individual facility component. The indicators tested in the SPIN project are contained in Table 4(a) and those recommended by IAEA [10] in Table 4(b).

National nuclear repository R\&D programs on the safety and performance studies carried out for different geological host formations in Belgium, Germany, France, Sweden, Switzerland, and USA can be found on the websites of Belgium National Institute for Radioactive Waste and Enriched Fissile Materials (NIRAS), German Bundesamt für Strahlenschutz (BfS), French National Radioactive Waste Management Agency (ANDRA), Swedish Nuclear Fuel and Waste Management (SKB), National Cooperative for the Disposal of Radioactive Waste in Switzerland (NAGRA), and Sandia National Laboratories, respectively.

The SPIN project concludes that the safety indicators show how safe a geological repository is, provided relevant reference values are available [20]. The alternative safety indicators provide additional information about the overall performance of the repository. These indicators are more reliable than calculated dose rates in the far future because the evaluated measures relate to the behavior of the engineered and geological barriers, which are less liable to uncertainties than the biosphere. The effective dose rate remains nevertheless the baseline safety indicator.

Safety and performance indicators also appear as a very important communication tool that is likely to contribute to public acceptance of geological repositories. Specialists can indeed use these indicators to show how such repositories work and are thus better equipped to convey to the public their assessments of the repositories' safety [20].

1.5. Review of Proposed Criteria for Away-from-Reactor Storage Strategy. Project needs and selection criteria for awayfrom-reactor storage facilities were elaborated by IAEA and are included in the Annex to the IAEA Guidebook in "Selection of Away-From-Reactor Facilities for Spent Fuel Storage" [17]. The selection process begins with the statement of the demand and ends with the screening and ranking of different options performed on the basis of multiattribute and multistakeholder decision aid methodology. As a decision support a multiple-criteria decision-making framework is recommended to be applied when a large number of conflicting criteria and a large number of stakeholders are going to be involved.

The multiple-criteria decision-making is both a social and a managerial task. Therefore, an analyst applying corresponding methods must take facts and values into account. Trading-off between social factors and environmental factors is an example. Decisions on the strategy and its consequences, for instance, building the nuclear infrastructure associated with waste management "political" options, are usually multidimensional. The decision-making requires therefore modeling and integration of technical, social, economic, and environmental aspects into a multiple objective planning and management process. This has been proven in [21] while discussing the case study on the selection of nuclear waste repositories in UK. 
TABLE 4

(a) Safety and performance indicators tested in the SPIN project [20]

Safety indicators

Effective dose rate [Sv/y]

Radiotoxicity concentration in biosphere water $\left[\mathrm{Sv} / \mathrm{m}^{3}\right]$

Radiotoxicity flux from geosphere [Sv/y]

Radiotoxicity outside geosphere [Sv]

Time-integrated radiotoxicity flux from geosphere [Sv]

Relative activity flux from geosphere [-]

Relative activity concentration in biosphere water [-]
Performance indicators

Activity in compartments $[\mathrm{Bq}]$

Activity outside compartments [Bq]

Activity flux from compartments [Bq/y]

Time-integrated activity flux from compartments $[\mathrm{Bq}]$

Activity concentration in compartment water $\left[\mathrm{Bq} / \mathrm{m}^{3}\right]$

Radiotoxicity in compartments [Sv]

Radiotoxicity outside compartments [Sv]

Radiotoxicity flux from compartments [Sv/y]

Time-integrated radiotoxicity flux from compartments [Sv]

Radiotoxicity concentration in compartment water $\left[\mathrm{Sv} / \mathrm{m}^{3}\right]$

Transport time through compartments [y]

Portion of not totally isolated waste [-]

Time-integrated flux from geosphere/initial inventory [-]

Concentration in biosphere water/waste package water [-]

(b) IAEA: examples of performance and safety indicators [10]

\begin{tabular}{lccc}
\hline Indicator & Source & Application & "Yardstick" \\
\hline Radionuclide transfer times & General performance indicators & Radionuclide half-lives \\
of parts of total system & $\begin{array}{c}\text { E.g., clay backfill) or } \\
\text { geosphere }\end{array}$ & Radive evaluations
\end{tabular}

Radionuclide concentrations in the near field
Assessment model results
Engineered barrier system

Subsystem criteria derived from sensitivity analyses ("relative" comparisons between different analyses may also be of value, see main text)

Characteristics that control "dilution" in time and space (e.g., waste-form dissolution or release rates, canister failure rate, and porosities)

Age profile of groundwater

Other physical-chemical properties of the disposal system (e.g., water package loading, buffer composition and density, fracture frequency, and lack of exploitable mineral resources

\begin{tabular}{|c|c|c|c|}
\hline \multicolumn{4}{|c|}{ Safety indicators } \\
\hline Risk & $\begin{array}{l}\text { Assessment model } \\
\text { results }\end{array}$ & Human beings & Risk limit or constraint \\
\hline Dose & $\begin{array}{l}\text { Assessment model } \\
\text { results }\end{array}$ & Human beings & Dose limit or constraint \\
\hline Environmental impact & $\begin{array}{l}\text { Assessment model } \\
\text { results }\end{array}$ & Other species & $\begin{array}{c}\text { Environmental protection } \\
\text { standards }\end{array}$ \\
\hline \multicolumn{4}{|c|}{ Complementary safety indicators } \\
\hline $\begin{array}{l}\text { Radionuclide concentrations outside } \\
\text { the near field }\end{array}$ & $\begin{array}{l}\text { Assessment model } \\
\text { results }\end{array}$ & Accessible environment & $\begin{array}{c}\text { Levels of corresponding natural } \\
\text { concentrations }\end{array}$ \\
\hline $\begin{array}{l}\text { Radionuclide fluxes outside the near } \\
\text { field }\end{array}$ & $\begin{array}{l}\text { Assessment model } \\
\text { results }\end{array}$ & $\begin{array}{c}\text { Accessible environment, } \\
\text { geosphere-biosphere } \\
\text { interface }\end{array}$ & Corresponding natural fluxes \\
\hline Containment times & $\begin{array}{l}\text { Experiments, technical } \\
\text { specifications, and/or } \\
\text { process model } \\
\text { calculations }\end{array}$ & $\begin{array}{l}\text { Canisters/containers, } \\
\text { engineered barriers, or } \\
\text { geosphere }\end{array}$ & $\begin{array}{c}\text { "Crossover times," for hazard } \\
\text { indices }\end{array}$ \\
\hline
\end{tabular}

Criteria derived from total system performance-assessment calculations geosphere Geosphere

Time-scale of assessment
Engineered barriers or geosphere
Subsystem criteria developed by the regulatory authority or by the operator ecifications, and/or process model calculations Site characterization paleohydrogeology

Experiments, technical

Experiments, technical pecifications, and/or process model calculations 


\section{Background Information on Multiple-Criteria Decision-Making}

Integrated analyses and foresight studies towards nuclear energy deployment, assessment of its role in sustainable development and planning of nuclear energy programs, and nuclear infrastructure are multistep procedures. In the first step a selection of criteria in different areas, for instance, safety, resource utilization, economy, proliferation resistance and physical protection, waste management, environment, infrastructure, is required. In the next step, alternatives should be identified. Finally, a suitable multicriteria method has to be selected that is adequate for making comparative judgements about the attractiveness of chosen alternatives on the basis of their performance indicator values on defined criteria [22]. In this process, conflicting criteria are often involved implying that an improvement in the indicator value on one criterion entails performance deterioration of an option on other criteria. A crucial step in the decision aiding-process is the aggregation of the judgements about the alternatives' performances on each criterion which should faithfully model the overall preferences of both stakeholders and technical experts $[21,23,24]$.

Ranking of alternatives and a selection of the most attractive one can be performed either in a nonformalized way, that is, based on expert intuition and experience, or using the formal multiple-criteria decision-making (MCDM) aid. MCDM helps to structure the problem and to highlight conflicts. Structured representation of the problem situation facilitates trading-off during the decision-making process [25-27]. The formalized procedure seems to be more attractive because it gives an opportunity to compare alternatives on a wellreasoned quantitative basis and to justify the selection of the most convenient trade-off alternative. Furthermore, it is essential to make analyses of subjective and objective uncertainties and assess their impact on the ranking results in order to improve robustness, that is, the validity of judgements.

Multicriteria decision analysis (MCDA) and multiobjective decision-making (MODM) constitute the two main classes of MCDM (see Table 5). These two classes differ in their approach to (1) the structure the multicriteria problem that is going to be tackled and (2) the way the problem is being solved. MCDA solves the problem by selecting the best alternative among the given alternative set (ranking approach) whereas MODM looks for a set (sometimes infinite) of all possible alternatives (design approach).

Provided that a finite number of alternatives under consideration (e.g., specific repository sites and SNF storage facilities) are explicitly defined and the performance of each alternative on a given set of criteria is assessed, ranking and selection of the most attractive option can be carried out using the MCDA methods (MAVT/MAUT, AHP, TOPSIS, PROMETHEE, etc.). These methods have been already widely applied for supporting decision-making in various subject areas including nuclear engineering [28]. A basic problem is to find the best decision rule incorporating the experts' preferences. This rule will provide a ranking of a finite set of identified alternatives (explicitly defined) combining the performance indicators with the expert preference values.
Note that the MCDA does not provide the absolutely "best" solution to the problem, because while comparing alternatives, tradeoffs are allowed; that is, an alternative A can compensate its worse performance in comparison to alternative $\mathrm{B}$ on a particular criterion $\mathrm{C}-1$ judged as being less worth than criterion $\mathrm{C}-2$ by its better performance on criterion C-2. MCDA methods have been already applied in both international collaborative projects (launched by IAEA, OECD/NEA) and national studies conducted by the US Department of Energy [28] or NIREX [24] for the judgement aggregation and the decision support on technology and scenario levels. For instance, in the collaborative project "Key Indicators for Innovative Nuclear Energy Systems" (KIND) of the INPRO/IAEA section, recommendations were made on how to use MCDA for a comparative analysis of nuclear energy systems performance in view of sustainability. These recommendations allow ranking system performance at the technology and even scenario levels including some nuclear waste management issues [29, 30].

MODM applies to decision problems in which the alternative set is not explicitly known. An alternative (e.g., technical characteristics of repository sites and options for resources allocation) is to be found by solving a corresponding optimization problem with well-defined constraints on alternatives. In MODM, the number of alternatives may be either infinite or not countable (continuous decision space) and the objectives are expressed by quantifiable objective functions. MODM models therefore are vector optimization problems with respect to objective functions which are simultaneously optimized. Essential to this class is the concept of a set of nondominated alternatives. The nondominated set of alternatives can be informally defined as a subset of those alternatives for which the performance value on any one of the specific optimality criteria may only be improved by degrading the performance value on at least one of the remaining criteria. Thus, any alternative belonging to the nondominated set cannot be improved by all the specific optimality criteria simultaneously. The MODM methods use trade-off curves to determine the directions for structural changes in the system in order to optimize its performance.

\section{MCDA Decision-Making Framework for Nuclear Waste Management Strategy Selection}

3.1. Problem Statement. Experts determine the attractiveness of different nuclear waste management options in regard to technical, economic, institutional, political, and public acceptance aspects. In practice, there is a competition between various aspect-oriented areas and even between measures within a certain area, which, for instance, may lead to a reduction of long-term risks while increasing short-term ones. At present, there are neither universal, reliable, and generally accepted numerical criteria nor methods for comparative evaluation of nuclear waste management options in all of the abovementioned aspects. The selection of the most promising alternative is a wicked problem involving expert judgements and decision-maker preferences which must be taken into account. At the same time and on the local scale, many 
TABLE 5: The most commonly used MCDM methods.

\begin{tabular}{|c|c|}
\hline MCDA methods & MODM methods \\
\hline \multicolumn{2}{|c|}{ Specific features } \\
\hline $\begin{array}{l}\text { MCDA provides a comparison of a relatively small number of } \\
\text { alternatives, prespecified by indicators/attributes, by ranking of } \\
\text { alternatives. Decision-makers and experts' preferences and intentions } \\
\text { are embedded as weight and preference functions (single-attribute, or } \\
\text { generalized criterion preference) }\end{array}$ & $\begin{array}{l}\text { Within MODM, the numerous and not explicitly defined } \\
\text { alternatives are simultaneously considered. Different optimization } \\
\text { techniques with constraints are applied for searching for the best } \\
\text { alternative. Multiple objective functions are to be defined which in } \\
\text { general lead to vector-maximum problems }\end{array}$ \\
\hline \multicolumn{2}{|c|}{ Classification of specific methods } \\
\hline $\begin{array}{l}\text { Elementary methods } \\
\text { (i) Simple additive weighting } \\
\text { (ii) Kepner-Tregoe method } \\
\end{array}$ & $\begin{array}{l}\text { No preference methods } \\
\text { (i) Global criteria } \\
\text { (ii) Goal programming }\end{array}$ \\
\hline $\begin{array}{l}\text { Value-based methods } \\
\text { (i) MAVT } \\
\text { (ii) MAUT } \\
\text { (iii) AHP } \\
\end{array}$ & $\begin{array}{l}\text { A priori methods } \\
\text { (i) Criteria constraints method } \\
\text { (ii) The achievement scalarizing function } \\
\text { (iii) The weighted sum }\end{array}$ \\
\hline $\begin{array}{l}\text { Outranking methods } \\
\text { (i) ELECTRE } \\
\text { (ii) PROMETHEE } \\
\text { (iii) QUALIFLEX } \\
\end{array}$ & $\begin{array}{l}\text { A posteriori methods } \\
\text { (i) ADBASE } \\
\text { (ii) Normal constraint method } \\
\text { (iii) Directed search domain }\end{array}$ \\
\hline $\begin{array}{l}\text { Reference point based methods } \\
\text { (i) TOPSIS } \\
\text { (ii) VIKOR } \\
\text { (iii) BIPOLAR }\end{array}$ & $\begin{array}{l}\text { Adaptive and interactive methods } \\
\text { (i) Genetic algorithms (NSGA-II, MOCHC, etc.) } \\
\text { (ii) Feasible and reasonable goals methods } \\
\text { (iii) Parameter space investigation (PSI) method }\end{array}$ \\
\hline
\end{tabular}

national studies on repository site selection with detailed repository safety and performance investigations have been done.

\subsection{Problem Structuring. Any integrated analysis of the} nuclear waste management policy options related to performance, safety, and sustainability assessments strives to be pluralistic. It has to coherently accept different priorities, intentions, values, and norms. The analysis has to rely on a consensus about both the hierarchy of requirements and the basic principles. A basic principle is a statement of a general goal that is to be achieved. Basic principles serve to provide broad guidance for deployment of corresponding technological options. Therefore, in this paper basic principles will be used as a point of departure for hierarchical modeling of objectives which will be further used to guide the decisionmaking process.

3.3. Identifying High- and Low-Level Objectives. Conscious decision needs clear objectives. To build the objective structure tree, nuclear energy basic principles (BP) proposed by the IAEA will be applied here. BP may be subdivided into three main categories: beneficial, responsible, and sustainable use [31]. The beneficial use category includes two BP, benefits and transparency; hence the use of nuclear energy should provide benefits that outweigh the associated costs and risks and should be based on the open and transparent communication of all relevant information. The sustainable use category includes two BP, (1) resource efficiency and (2) continual improvement, which means the efficient resource use and the utilization of nuclear energy such that, while reducing environmental impact, it pursues advances in technology and engineering to continuously improve safety, security, economics, and proliferation resistance. The third, responsible use category encompasses four BP: the protection of people and the environment, security, nonproliferation, and long-term commitment in compliance with internationally recognized standards.

IAEA also formulated specific objectives for the area of nuclear waste management shown in Table 6 and recommended using them at different implementation stages of nuclear programs [11]. These general basic principles and objectives can be adapted for a specific problem and serve as basic concepts guiding elaboration of more detailed problemand practice-oriented lower-level objectives and criteria.

On the basis of two-level objective structure depicted in Table 6, the criteria set will be proposed here to be further used to perform comparative evaluations of nuclear waste management strategy options.

3.4. Identifying Options for Achieving the Objectives. The purpose of this section is to identify options that may contribute to the achievement of objectives contained in Table 6. The overall goal is to develop a framework for hypothetical case studies showing how MCDA could support setting nuclear waste management policies in newcomer countries [32]. The lower-level criteria, which must meet the objectives, will be used to compare the options. In general, options may range from broad policies through the strategy choice up to selection of individual national repository site. One area of focus is on the waste management strategies, assuming that each potentially sensible option, if chosen, needs to be developed in detail later on at a national level. In this sense, technical performance and safety comparisons of 
TABLE 6: Proposed hierarchical objective structure for comparison of nuclear waste management strategies taking into account IAEA categories [11].

\begin{tabular}{|c|c|c|}
\hline $\begin{array}{l}\text { High-level } \\
\text { objectives }\end{array}$ & Category & Objective \\
\hline \multirow[b]{2}{*}{ Beneficial use } & Benefits & Minimization of generation and optimization of the management of radioactive waste \\
\hline & Transparency & $\begin{array}{l}\text { Establishment of methods and approaches for building trust among persons involved } \\
\text { in and affected by the management of radioactive waste }\end{array}$ \\
\hline \multirow{2}{*}{ Sustainable use } & Resource efficiency & $\begin{array}{l}\text { Promotion of radioactive waste management methods and schemes that save } \\
\text { resources and utilize them efficiently }\end{array}$ \\
\hline & $\begin{array}{c}\text { Continual } \\
\text { improvement }\end{array}$ & Constant improvement of methods and technologies in radioactive waste management \\
\hline \multirow{4}{*}{ Responsible use } & $\begin{array}{l}\text { Protection of } \\
\text { people and the } \\
\text { environment }\end{array}$ & $\begin{array}{l}\text { Implementation of radioactive waste management methods that ensure the protection } \\
\text { of people and the environment }\end{array}$ \\
\hline & Security & Implementation of physical protection systems relevant to radioactive waste \\
\hline & Nonproliferation & $\begin{array}{c}\text { Incorporation of nuclear safeguard requirements in the design and operation of } \\
\text { radioactive waste management facilities }\end{array}$ \\
\hline & $\begin{array}{l}\text { Long-term } \\
\text { commitment }\end{array}$ & $\begin{array}{l}\text { Development of solutions that provide for the long-term management of radioactive } \\
\text { waste }\end{array}$ \\
\hline
\end{tabular}

different repository sites are out of the scope of this paper, but obviously, these would be important issues if national HLW repository options were preferred.

Discussions and reviews presented in Section 1 allow selecting the three most representative waste management strategy options having a potential to contribute to the achievement of identified objectives:

(1) Interim storage at and/or away from reactor site for the next 100 years

(2) Interim decay storage followed in midterm by a HLW disposal in a national repository

(3) HLW final disposal in a multinational repository.

3.5. Identifying the Criteria to Be Used to Compare the Options. In this step, the performance comparison of the different options will be addressed in order to meet the objectives listed in Table 6. This task requires the selection of criteria to reflect the performance in meeting the objectives. Each criterion must allow defining measurable metrics/indicators to assess, at least in the qualitative sense, how a particular option is expected to perform in relation to the criterion. Three criteria have been identified for each category as shown in Table 7.

3.6. Analysis of the Option Performance. For illustrative purposes, the performance evaluation of an option on a particular criterion was expressed here in "best guess" preference scores assigned on the three-point scale. The direct assessment method was used to obtain these preference scores; that is, scores were judged directly by the authors for all attributes and compiled in the performance table. This approach is known as an ordinal (rating) scale representing values 1, 2 , and 3 that belong to a predefined ordered set, assuming that value " 1 " is less attractive than value " 2 ," value " 2 " is less attractive than value " 3 ," and so on. Specified scoring scale values assign to each option a rating to demonstrate to which extent it satisfies a particular performance criterion. For example, within a 3-point scale, it might be as follows: 3 , excellent; 2, satisfactory; 1, poor; see column "Options" in Table 7.

Any other scales, for instance, five-point or ten-point scales, can be applied instead. Thus, the scale range applied in the paper can be changed. It can be established in a different way and even be modified, if necessary, in the course of the analyses. The ranges of scales reflect differences in strength of preference for each indicator/metric/attribute. Therefore, more sophisticated difference scaling techniques can be used for assessments if the preference between option1 and option- 2 is not equal to the preference between option- 3 and option- 2 and that difference in preferences might be one consideration in accessing weights later on.

3.7. Ranking Results and Sensitivity Analysis. After scoring, for further differentiation of the options, it is necessary to get information about the preferences of experts and decisionmakers on the relative importance of criteria, weights. The authors skip this stage and apply the so-called "base-case" weights (i.e., "equal weights") as presented in Table 8.

The "equal weights" method may be considered as the first approximation within the MCDA problem. It depicts a situation when nothing is known regarding experts'/stakeholders' and decision-makers' preferences on the relative importance of criteria. However, even if the detailed information regarding expert weights is not available, the "equal weights" judgement in combination with detailed weight sensitivity analysis provides a chance to make a general conclusion about the attractiveness of the options in many different perspectives.

A key feature of decision modeling is the iterative way of proceeding that allows different local perspectives to be simulated by means of diverse sets of weights. It is worth to notice that just the base-case weights can be changed 


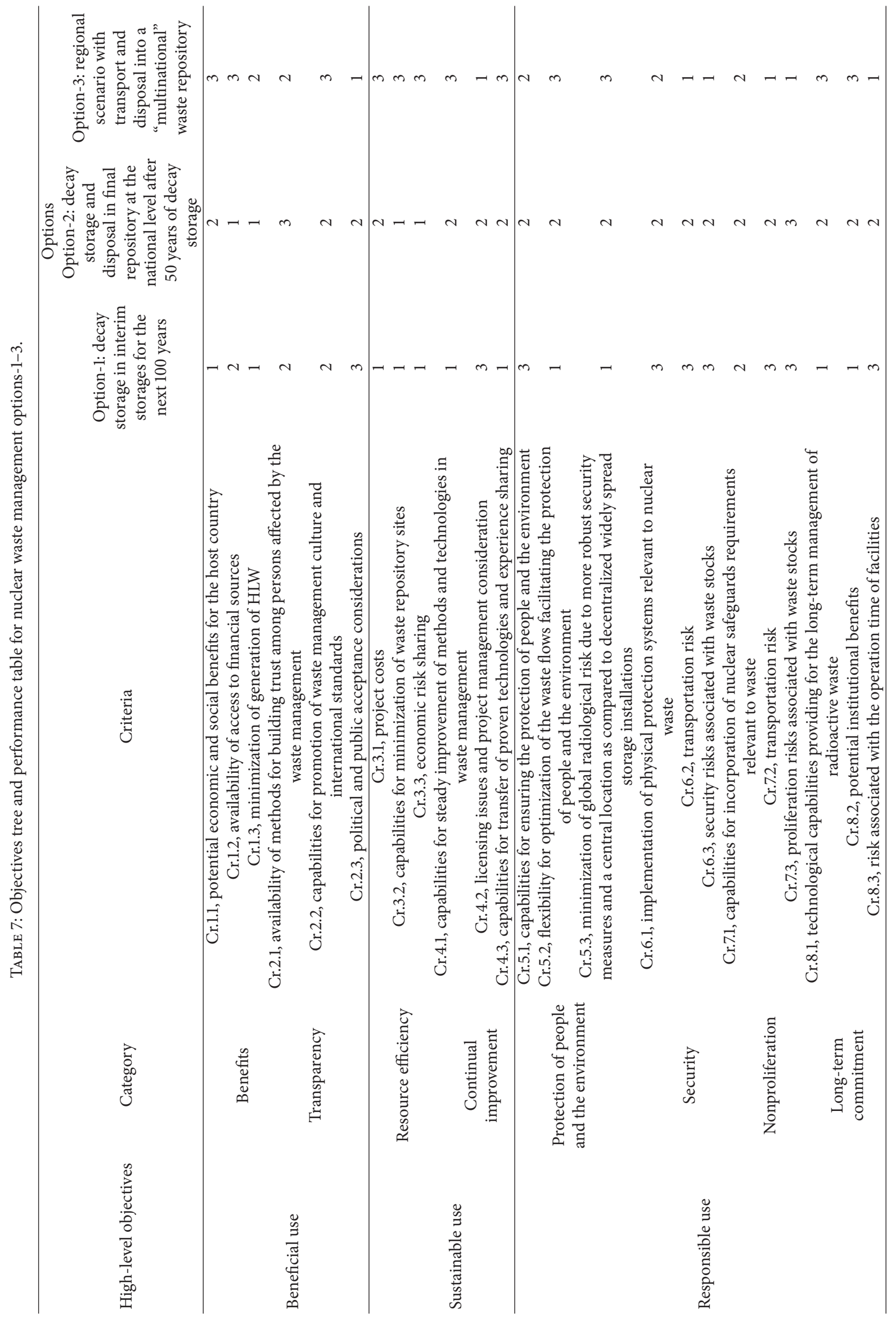


TABLE 8: Base-case weights option (“equal weights”).

\begin{tabular}{lccccc}
\hline Objectives & Objectives weights & Categories & Categories weights & Criteria abbr. Criteria weights & Final \\
weights
\end{tabular}

to simulate the perspectives of different interest groups and assess the impact on the overall ranking scores. The authors intentionally did not perform such examinations within the case study, because this would require accounting for the specifics of national preferences and standpoints on nuclear energy development and waste management issues. Nevertheless, a sensitivity analysis of ranking results with respect to high-level objective weights was carried out to demonstrate ranking order sensitivity to different possible variants of weights.

3.7.1. Value Path. Value path is a graphical visualization way of a performance matrix which represents performance values of options against all criteria. It is useful for the identification of nondominated and/or dominated options. An option is "dominated" if its performance scores on the entire set of criteria are worse than the performance scores of other options. Dominated options can be excluded from consideration. This facilitates comparison and makes the ranking results more stable. Value path for the considered decision problem is shown in Figure 3. There are only nondominated options in the considered set.

The advantage of this preliminary type of analysis is that there is no need to determine the weights yet. On the other hand, the identification of the set of nondominated alternatives does not allow their ranking. In order to rank the alternatives, it is necessary to apply a decision rule utilizing (1) weights which reflect the relative importance of criteria for experts/stakeholders and decision-makers and (2) numerical weights (value functions) assigned to define the relative valuations over a range of the chosen attribute scale for each criterion.

MAVT was chosen in this paper as the reference method, because attributes are mutually preference-independent and in this case MAVT offers a possibility to implement the measurable value functions and apply the additive rule for judgement aggregation (additive form of the multiattribute value function). Moreover, the MAVT provides an assessable resolution grade of ranked options and a feasibility of breaking-down the overall score into the partial scores for composed indicators. These features facilitate an interpretation of the results.

3.7.2. Results of MAVT Method Application, Sensitivity, and Uncertainty Analyses. Figure 4(a) demonstrates the MAVT ranking results for equal weights model. Shares of highlevel objectives scores to the overall score are shown for each option. The radar chart (Figure 4(b)) illustrates score shares of individual categories (see Table 6 for criteria, categories mapping). Linear single-attribute value functions 


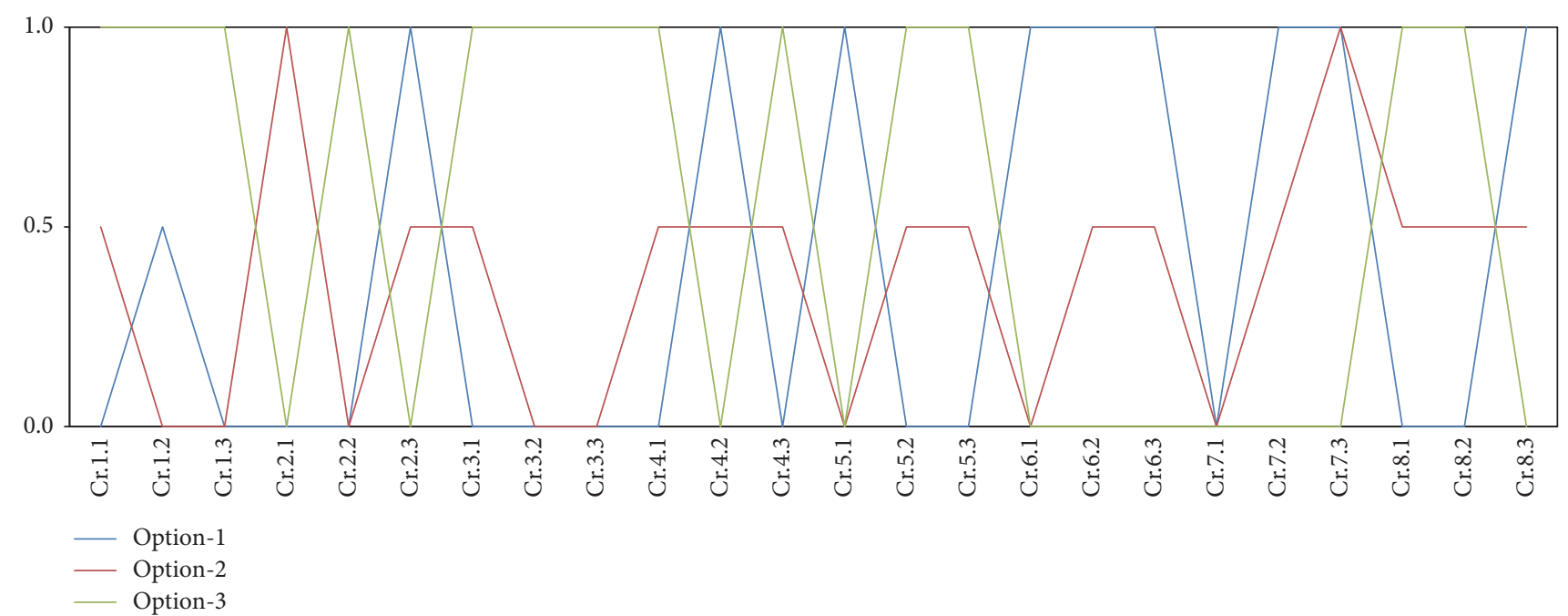

Figure 3: Value path.

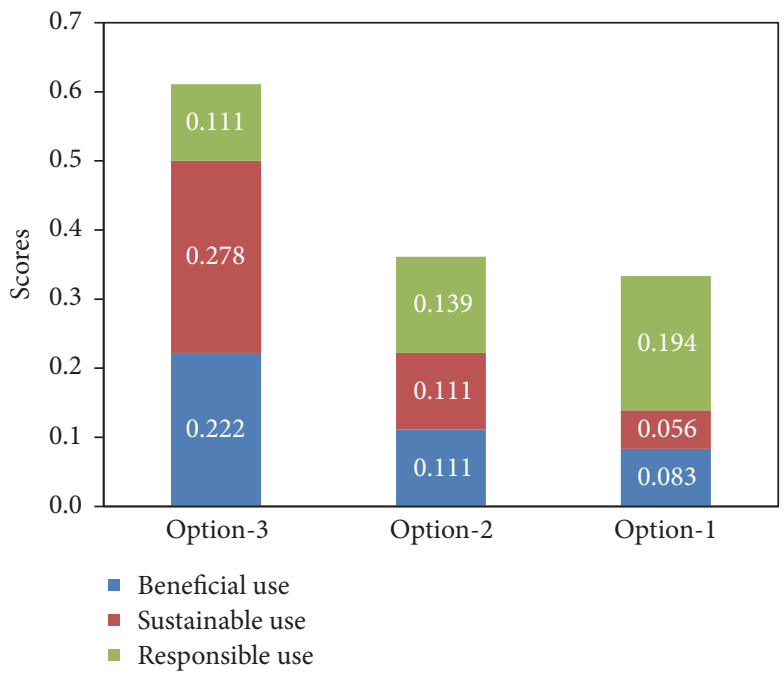

(a)

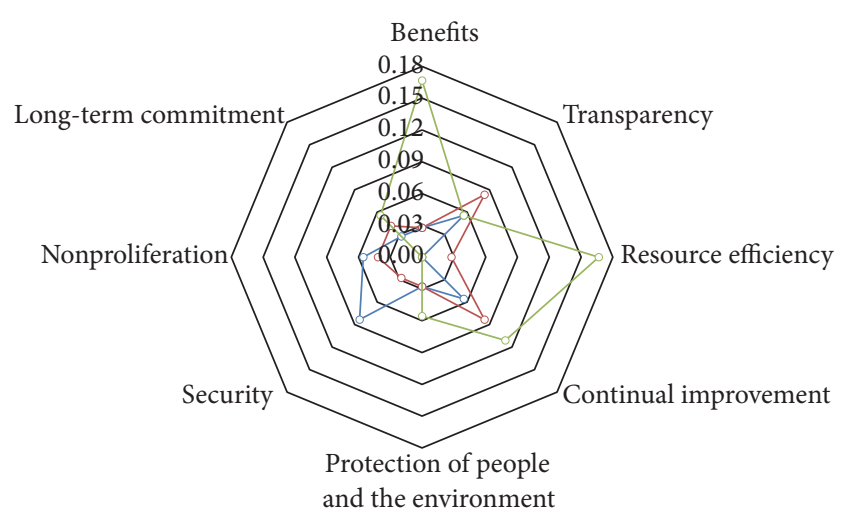

$\multimap$ Option-1
- Option-2
- Option-3

(b)

FIGURE 4: MAVT ranking results for equal weights with breakdown of the total scores into high-level objectives scores (a) and radar chart with shares of individual categories (b).

reflecting relative expert valuations for each criterion were applied in the MAVT model. Before, it was observed that the ranking results are not sensitive in regard to the shape of single-attribute value functions defined on local attribute performance scales. Additional investigation was done on the impact of the range of local scoring scales (5- and 10point scales) for indicators on the ranking results, and the outcomes confirmed that options' ranks were not sensitive to the number of discrete points used in local scoring scales.

Among three analyzed options, option-3 performs the best on a set of selected criteria (its overall score equals 0.611 ). Option- 2 and option-1 reach nearly equal total scores and are on the second and third ranking positions with the overall scores equal to 0.361 and 0.333 , respectively. To explain the ranking results better, the overall scores were broken down into individual constituents in accordance with the objective hierarchy structure (see Table 6). Individual scores for high-level waste management objectives ("beneficial use," "sustainable use," and "responsible use") can be taken from Figure 4(a). Analysis of these partial scores allows interpreting the highest potential of option-3 (best strategy) as follows: Option-3 got the worst aggregated score on the high-level objective "responsible use" as compared to option2 and option-1; the "responsible use" partial scores are equal to $0.194,0.139$, and 0.111 for option-1, option-2, and option3 , respectively. On the other hand, this alternative (option3) has the best scores for "beneficial use" and "sustainable use." The "beneficial use" scores are 0.083 (option-1) < 0.111 (option-2) $<0.222$ (option-3), whereas the "sustainable use" scores are 0.056 (option-1) $<0.111$ (option-2) $<0.278$ 

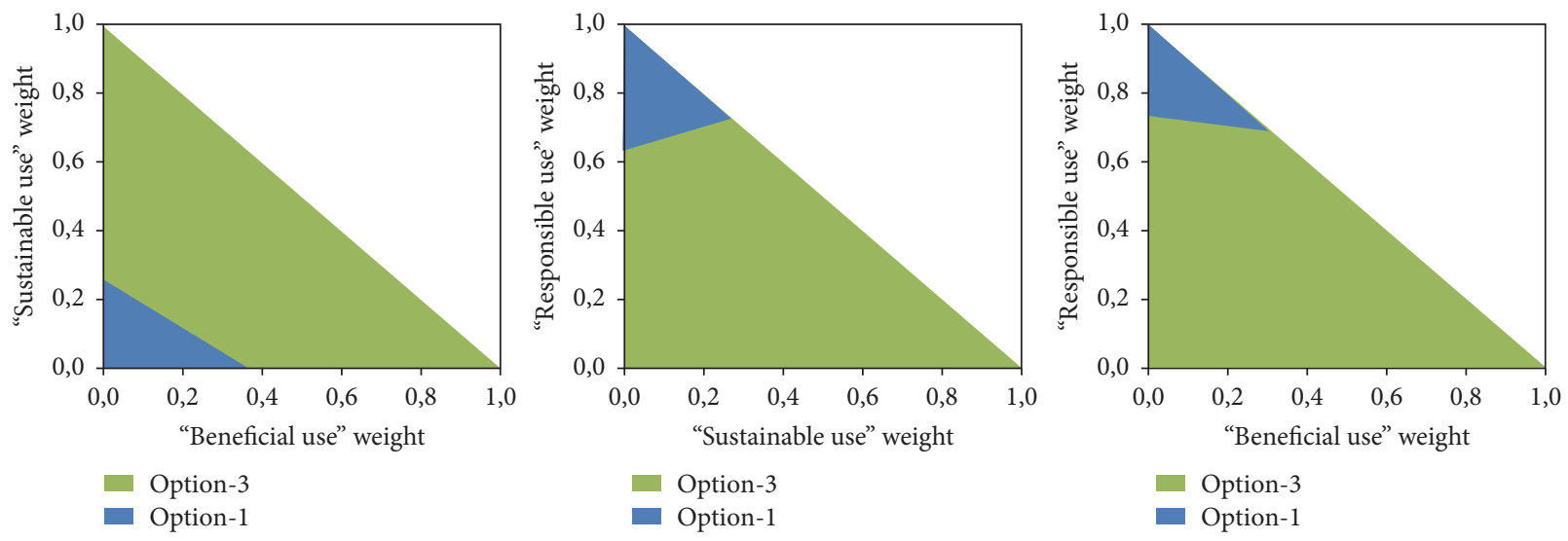

FIGURE 5: Results of a sensitivity analysis with regard to high-level objectives weights.

(option-3). As a result, option-3 finally takes the first rank because the worst performance on one high-level objective is compensated by the best performances on the other two.

If decision-makers and experts seek for still more comprehensive clarification of ranking results with even more details, the overall scores should be broken down into partial scores obtained for an individual assessment category, that is, benefits, transparency, resource efficiency, continual improvement, protection of people and the environment, security, nonproliferation, and long-term commitment. In this case, representation of ranking results shown in Figure 4(b) helps to visualize options' scores for each assessment category. In Figure 4(b), the radar chart compares for each strategy option multiple quantitative variables (partial scores) for eight categories represented on axes starting from the center midpoint of spiders' web. This chart clearly illustrates (in relative terms) the merits and demerits related to considered options. Moreover, it allows identification of the most vulnerable assessment area for each option.

The ranking results show that option-3 multinational repository for HLW final storage seems to be the most attractive waste management strategy for a "small" newcomer or waste-owner country. Stakeholder opinions and valuations (here termed as local perspectives) can be modeled using different sets of criteria weights and shapes of single-attribute value functions. Such analyses require, however, the stakeholder judgements which are subjective and tailored to local national conditions. In order to cope with this problem (no access to national preferences), extensive sensitivity analyses of ranking results with respect to the high-level objective weights were performed.

The results of these sensitivity studies are presented in Figure 5. To obtain this figure, weights for the three highlevel objectives were simultaneously varied over a range from 0 to 1 . As the weights must fulfil the normalization condition constraining their sum to 1 , only two of them, $w_{1}$ and $w_{2}$, can be independently chosen, whereas the third is calculated as $w_{3}=1-\left(w_{1}+w_{2}\right)$. The most favoured nuclear waste management options were identified using MAVT with the corresponding weights for sustainable use and beneficial use category $\left(w_{1}, w_{2}\right)$ varied as independent uniformly distributed variables over $[0,1] \times[0,1]$. Coloured areas demonstrate the weights combinations for which option-1 and option- 3 take the first rank. The colour contour graph shows that, in the area of $[0,0.38] \times[0,0.22]$, option- 1 has the highest rank. Beyond this region, option-3 takes the best position in ranking. Thus, this picture demonstrates a map of preferences (weights) and provides better understanding of how promising and robust each option ranking is in view of high-level objectives weights. The performed analysis shows that none of the high-level objective weights combinations may lead to option-2 at the top of the ranking order. A similar exercise was performed choosing $\left(w_{1}, w_{3}\right)$ or $\left(w_{2}, w_{3}\right)$ as independent weight parameters and identifying promising options for beneficial versus responsible use or sustainable versus responsible use, respectively.

Additionally, it is interesting to address the robustness of ranking results taking into account the uncertainties in the weight selection utilizing a box-and-whisker plot. Studies carried out under the program of the US Department of Energy [33] recommend using a stochastic weight generation procedure which shall be additionally implemented to treat the uncertainties related to weights values. The stochastic analysis allows generating ranking results in spite of the absence of final information usually gained by means of expert-stakeholder elicitation in an iterative process.

Just to recall, as the significance of individual criteria values for stakeholders (i.e., the local perspective) depends on a country and its citizen policies, the authors had to assume equal weights in the hypothetical approach. Thus, stochastic variation of weights will allow determining the preference probability distribution function of each option.

In this paper, a probabilistic formulation is applied to the case where (1) there is no information about the priorities (weights) and (2) there is a need to estimate the probability of option ranking order for different groups of expert views on the importance of criteria (stakeholder preferences). If it is assumed that all of the weights are randomly uniformly distributed in the range from 0 to 1 , constrained only by normalization conditions, and for each weight combination 
the MAVT assessment is performed for both objective tree and options given, the most attractive option can be selected, and the risks of making the worst decision can be estimated.

In other words, such an approach is a sort of probabilistic sensitivity analysis used for evaluating the probability distributions of options' scores and ranks, taking into account uncertainties in the relative significance of individual criteria (weights). Based on these probability distributions, it is possible to rank options under specified uncertainties, determine the preference probability of a certain option, and potentially evaluate the risks of making an ineffective decision.

The authors underline once more that this method implies that a problem is considered in a probabilistic formulation: when no or limited information is available about the priorities (weights) and when it is of interest to evaluate the probability of ranking options by different groups of experts who have different views on the importance of criteria. Using all the other assumptions unchanged, it will be assumed here that all of the weights are uniformly distributed in the range from 0 to 1 . Based on this approach probability distributions may be obtained by means of Monte Carlo simulations used to assess the probability of rank-ordering of alternatives. For reliable estimation of probability distributions of the options' scores and ranks, 10,000 weight combinations were generated by the Monte Carlo method.

Figure 6 demonstrates ranking results for three options analyzed here assuming a presence of uncertainties in the weights (as the box-and-whisker plot). Box-and-whisker plots are a handy way to display numerical data broken into four quartiles, each one with an equal number of data values. In order to generate the plot, the median of the lower half of the dataset (quartile 1), the median of the dataset (quartile 2), the median of the upper half of the dataset (quartile 3), and so on, that is, 25th, 50th, and 75th and 5th as well as 95th percentile are used to represent the statistical distribution of obtained option scores. It is to be recalled that option- 2 took the second position in MAVT ranking while applying the "base-case" weights. The stochastic sensitivity analysis shows that the second rank for this option is rather stable. Moreover, Figure 6 confirms that option-3 still remains the most attractive one. Option1 is characterized by longer 5 th-95th percentile bar than option- 2 and takes the third position, that is, the lowest 50thscore being on the last ranking position. It could, however, be competitive with option-2 for some particular preference (weights) configuration.

\section{Robustness}

4.1. Comparison of Ranking Results Using Different MCDA Methods. The robustness of ranking results was furthermore analyzed using different MCDA methods (see Table 9) such as Simple Scoring Model (SSM), MAVT/MAUT, AHP, TOPSIS, and PROMETHEE instead of MAVT.

The overview of application of these methods to evaluation and aggregation judgement measures for performance comparison of nuclear energy systems can be found in [28, 34-45]. Methods' parameters were selected in accordance with recommendations discussed in [29]. As these methods

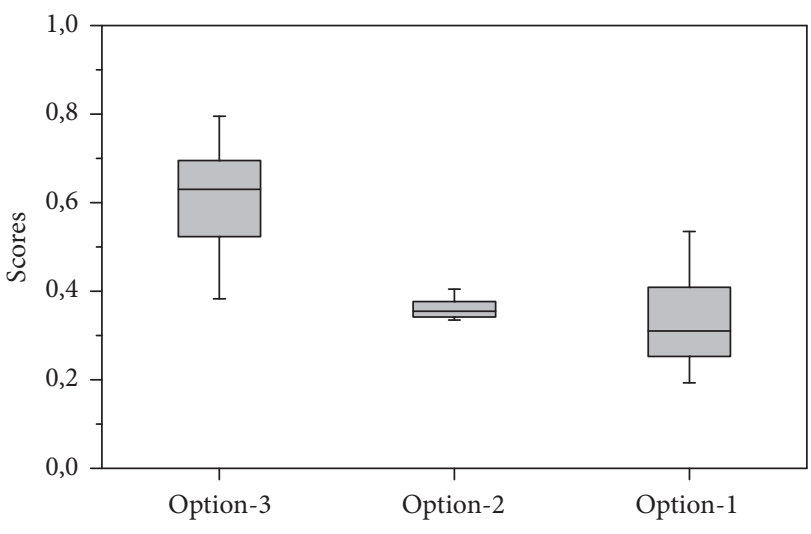

FIGURE 6: Ranking of options taking into account the uncertainties in the weights using the box-and-whisker chart (95th, 75th, 50th, 25th, and 5th percentile).

are based on different methodological approaches, their application significantly contributes to conclusions on the stability of ranking results with respect to the selection of a decision rule. Table 10 shows the ranking results (ranks) of options obtained using various methods in the "equal weight" case. As can be seen, the use of different methods leads to well-coordinated and identical ranking results.

4.2. MAVT versus PROMETHEE Results. As an example, the authors will discuss here in detail the comparison between the MAVT- based and Preference Ranking Organization Method for Enrichment Evaluations- (PROMETHEE) based decision support frameworks [25]. The most essential assumption of the MAVT approach is that decision-makers, stakeholders, and experts are aware of the utility/value of single attributes for each criterion and are able to express the relative importance of different criteria in a univocal way. The objective of decision-making technique is then to disclose and interpret the preferences of the decision-maker in transparent terms. In contrast, the other methods, especially methods based on outranking approaches like ELECTRE [25] and PROMETHEE [25], assume that decision-makers are not fully aware of their preferences and hence need a decision support in order to structure the process and an interactive help to demonstrate the impact of different criteria weightings. To facilitate comprehension, the PROMETHEE method features will be briefly presented here.

PROMETHEE performs pairwise comparisons of alternatives for each criterion. Thus, for each couple of alternatives $(a, b)$, the difference in criteria values $d$ for each criterion $f$ is determined at first $d(a, b)=f(a)-f(b)$; $d$ depends on the units of criterion $f$ and does not take yet into account intracriterion preference information of the expert/decisionmaker. Intracriterion preference information is embedded in PROMETHEE through the concept of generalized criterion. It requires the computation of preference degrees $P(a, b)$ which is performed as a mapping of $d(a, b)$ values into closed interval $[0,1] ; P: R \rightarrow[0,1]: d(a, b) \rightarrow P[d(a, b)] \cong P(a, b)$, where $P$ is a positive nondecreasing function such that $P=0$ for all $x<0$. The degree of preference of an alternative 
TABLE 9: Description of different MCDA methods applied to the examination of robustness.

\begin{tabular}{|c|c|}
\hline Method & Features \\
\hline $\begin{array}{l}\text { Simple Scoring } \\
\text { Model (SSM) [12] }\end{array}$ & $\begin{array}{l}\text { SSM is based on a linear additive model assuming that the overall score of a given alternative is evacuated as the } \\
\text { total sum of the performance score of each criterion multiplied by the weight of that criterion. }\end{array}$ \\
\hline $\begin{array}{l}\text { Multiattribute } \\
\text { Utility Theory } \\
\text { (MAUT) [13] }\end{array}$ & $\begin{array}{l}\text { MAUT uses utility, that is, probabilities and their expected values, in assessing a single attribute preference } \\
\text { function. Since the overall utility function for each alternative is a random variable, the ranking of alternatives } \\
\text { within MAUT is based on the comparison of expected utilities: A certain alternative is more attractive than the } \\
\text { other one if the expected value of the utility function for this alternative is greater than the expected values of } \\
\text { the other ones. Lotteries must be applied. }\end{array}$ \\
\hline $\begin{array}{l}\text { Technique for } \\
\text { Order Preference } \\
\text { by Similarity to the } \\
\text { Ideal Solution } \\
\text { (TOPSIS) [14] }\end{array}$ & $\begin{array}{l}\text { TOPSIS compares a set of alternatives by identifying weights for each criterion, normalizing scores for each } \\
\text { criterion, and calculating the geometric distance between each alternative and the ideal and anti-ideal } \\
\text { alternatives. TOPSIS is based on a concept that the more preferable alternative should have the shortest distance } \\
\text { from the most desirable (ideal) alternative and the longest distance from the less desirable (anti-ideal) } \\
\text { alternative. }\end{array}$ \\
\hline $\begin{array}{l}\text { Preference } \\
\text { Ranking } \\
\text { Organization } \\
\text { Method for } \\
\text { Enrichment } \\
\text { Evaluations } \\
\text { (PROMETHEE) } \\
{[15]}\end{array}$ & $\begin{array}{l}\text { PROMETHEE is an outranking method which implies forming a partially ordered relation between each pair of } \\
\text { alternatives. PROMETHEE is based on the generalization of criterion concept, with preference function } \\
\text { assigned to each criterion; see Section } 4.2 .\end{array}$ \\
\hline $\begin{array}{l}\text { Analytic Hierarchy } \\
\text { Process (AHP) [16] }\end{array}$ & $\begin{array}{c}\text { AHP is based on three principles: decomposition, pairwise comparative judgments, and synthesis of priorities. } \\
\text { Decomposition assumes the hierarchy elaboration for the given decision-making problem. Pairwise } \\
\text { comparative judgments assume pairwise comparisons of alternatives against each criterion using AHP scale. } \\
\text { Synthesis of priorities assumes determination of weights based on a pairwise comparison of criteria through } \\
\text { hierarchy and determination of scores (eigenvectors for the maximum eigenvalue, evaluation of the overall } \\
\text { score using a linear additive model). }\end{array}$ \\
\hline
\end{tabular}

TABLE 10: Options ranking results using different MCDA methods (“equal weights").

\begin{tabular}{lccccc}
\hline \multirow{2}{*}{ Rank } & \multicolumn{5}{c}{ Option\# } \\
& SSM & MAVT/MAUT & AHP & TOPSIS & PROMETHEE \\
\hline 1 & 3 & 3 & 3 & 3 & 3 \\
2 & 2 & 2 & 2 & 2 & 2 \\
3 & 1 & 1 & 1 & 1 & 1 \\
\hline
\end{tabular}

" $a$ " over an alternative " $b$ " can vary from $P(d)=0$ which means indifference, through weak preference, up to $P(d)=$ 1 indicating strong preference. The shape of generalized criterion preference function $P$ must be defined by the user. By default, six types of generalized criteria $(P, f)$ are offered in PROMETHEE toolkit: usual, U-shaped, V-shaped, level, V-shaped with indifference, and finally S-shaped (see [25] for details). These shape value functions may depend on two parameters specifying the indifference $q$ and preference $p$ thresholds. The indifference threshold $q$ is the largest value of $d$ which an expert considers negligible while comparing two alternatives whereas the preference threshold $p$ is the smallest value of $d$ which an expert considers as decisive. Instead of a single-attribute value function used in MAVT, an outranking relation $\pi$ is defined in PROMETHEE for each pair of alternatives; $\pi$ is a weighted sum of preference degree function values over all criteria:

$$
\pi(a, b)=\sum_{k=1}^{K} w_{k} \cdot P_{k}\left(f_{k}(a)-f_{k}(b)\right) .
$$

With weights normalized to $1, \pi$ can be interpreted as an aggregated composed indicator which measures the intensity of decision-maker preferences for alternative " $a$ " versus " $b$ " if all criteria are simultaneously considered.

As an indicator of strength for alternative $a$, the outgoing flow is calculated measuring the outranking character of alternative $a$

$$
\varphi^{+}(a)=\frac{1}{N-1} \sum_{b \in A} \pi(a, b) .
$$

As an indicator of weakness for $a$, the incoming flow is determined measuring the "outranked character" of $a$

$$
\varphi^{-}(a)=\frac{1}{N-1} \sum_{b \in A} \pi(b, a),
$$

where $A$ denotes a full set of discrete $N$ alternatives and obviously $b \neq a$.

PROMETHEE I method determines the partial preorders induced by $\varphi^{+}$and $\varphi^{-}$, PROMETHEE II delivers complete preorder, and eliminates potential incompatibilities using

$$
\varphi^{\text {net }}(a)=\varphi^{+}(a)-\varphi^{-}(a)
$$

as a balance between the outgoing and the incoming flows. The $\varphi^{\text {net }}$ flow aggregates the strengths and the weakness of an alternative to a single score. Among other MCDA methods which have been applied for the hypothetical case study, the results of PROMETHEE II ranking will be analyzed in detail. In PROMETHEE I and II, V-shaped, that is, linear preference, 
functions were chosen with indifference threshold parameter $p$ equal to the difference of maximal and minimal criteria values achieved for the given criterion $k$ by all alternatives. In this particular case, the preference function can be defined in the following way:

$$
P_{k}(d)= \begin{cases}0, & d<0 \\ \frac{d}{p_{k}}, & 0 \leq d \leq p_{k} \\ 1, & d>p_{k} .\end{cases}
$$

It can be analytically proven that differences between the preference $\varphi^{\text {net }}$ scores for two subsequent alternatives (higher scored alternative and lower scored alternative next to it) obtained with PROMETHEE II are equal to the differences between two aggregated utility scores for the corresponding alternative pairs obtained with the MAVT method. This allows concluding that the outranking preference models based on pairwise comparisons and MAVT model with additive aggregation and linear single-attribute value functions deliver in this case basically the same results.

Final remarks are as follows:

(1) Due to the limited scope of the study, the results of this basic analysis obviously cannot be seen as the platform for substantial management decisions; however, in the authors' opinion these results are quite illustrative and sufficient to demonstrate the basic methodological aspects related to the application of MCDA methods for ranking nuclear waste management strategy options helping to give recommendations.

(2) The main benefit of aggregation of expert and stakeholder evaluations applying formal mathematical methods is that such a procedure provides a possibility to structure the discourse and to organize an efficient expertise in an iterative process in order to find the most prospective nuclear waste management strategy/option and to demonstrate, on a quantitative basis, the merits and demerits of the compared alternatives giving well-reasoned judgements on their attractiveness.

(3) MCDA supported analysis could form the basis for management decisions and contribute to the elaboration of a concerted (trade-off) position on the most prospective nuclear waste management strategies, given expertise from both proponents and opponents of different concepts.

\section{Conclusions}

MCDA is able to support the comparative evaluation of options also in the field of nuclear waste management strategy. The MCDA includes screening, prioritizing, ranking, or selecting of the alternatives based on human judgement in terms of the multicriteria that are very often conflicting. The framework which the paper proposes to compare performances of selected waste management options uses objectives hierarchy structure, the performance indicators, the preference/value functions, the weights, and a judgement aggregation rule. The judgement aggregation delivers scores for each option leading to an overall ranking which may support a decision-making process. The hypothetical case study is performed by means of proposed methodology and the results are discussed in detail in order to demonstrate the MCDA application benefits in the policy/strategy selection process. For illustration, the authors focused on a newcomer country and assumed three specific waste management strategy options: (1) interim storage at and/or away from reactor site for the next 100 years, (2) interim decay storage followed in midterm by a disposal in a national repository, and (3) a disposal in a multinational repository. In the paper the three-point scale and the "best guess" scores are applied to assess each option performance on defined criteria. The scores were judged directly for each attribute and compiled in the performance table.

The scale range, however, can be established in a different way and can be modified in the course of the analyses, if necessary. Scales reflect differences in strength of preference for option performance level on criterion. Therefore, in practical situations, elicitation of preferences must be done before the evaluation is performed because these parameters allow determining the single-attribute preference/value function shape and the high-level objective weights, respectively. In the situation where a multigroup, "democratized" decision-making process is launched, opinions of different stakeholders, experts, and decision-makers groups can be easily incorporated into the framework using elicited weights; however, before attaching the "most reliable" weights to the criteria, a consensus within each group has to be obtained.

Stakeholders/experts valuations combined with performance indicators of options constitute a significant part of input for the proposed MCDA method. As in the paper a finite set of explicitly defined options is considered MAVT method was used for an aggregation. The MAVT approach includes mapping of each local attribute scoring scale into a common scale and the application of multiattribute judgement aggregation rule combining the indicators, the value functions, and the high-level objective weights to the overall scores. Linear single-attribute value functions were chosen here because the constant slope (first-order derivative value) implies an indifferent attitude of a decision-maker towards the changes of the rate of function values versus the incremental change of an indicator value.

The ranking results show that option-3, a multinational geological repository for HLW disposal, seems to be the most attractive waste management strategy for a "small" newcomer or waste-owner country. This ranking result is stable.

Extensive sensitivity analysis was done to examine the robustness with respect to value function shape. No significant impact on the ranking results was observed. Embedding other MCDA methods in the proposed framework instead of MAVT had no impact on the ranking order either. Additionally, stochastic analyses were performed based on the Monte Carlo method in order to treat the uncertainties in weight values and address their 
impact on the ranking order. The generated box-and-whisker chart demonstrates the same ranking order of options as that obtained in the "base-case" with equal high- and low-level objective weights but provides more information on ranking robustness by estimating preference probabilities.

The framework which the paper proposes offers a high degree of flexibility. Base-case weights and indicator scale ranges can be adapted to the particular needs and easily changed (refined). A key feature of decision modeling is, however, the iterative way of proceeding. Feedback from participants contributing to a decision-making process at each iteration step is an essential factor properly refining the model.

In summary, the presented study confirms that the developed framework is able to deliver a robust ranking for selected nuclear waste management strategy options. A conclusion is that a multinational repository option has a higher rank than a national repository option; that is, it seems to be the most attractive one from the perspective of a newcomer country. Option-1 storage at or away from reactor side is biased by greater uncertainty and therefore can take either the second or the third ranking position depending on the elicited weights values for a particular application.

\section{Abbreviations}

$\begin{array}{ll}\text { AHP: } & \text { Analytic Hierarchy Process } \\ \text { BP: } & \text { Basic principles } \\ \text { IAEA: } & \text { International Atomic Energy Agency } \\ \text { ILW: } & \text { Intermediate-level waste } \\ \text { INPRO: } & \text { International Project on Innovative } \\ & \text { Nuclear Reactors and Fuel Cycles } \\ \text { HLW: } & \text { High-level wastes } \\ \text { OECD: } & \text { Organization for Economic Cooperation } \\ & \text { and Development } \\ \text { KIND: } & \text { Key Indicators for Innovative Nuclear } \\ & \text { Energy Systems } \\ \text { LLW: } & \text { Low-level waste } \\ \text { MAVT: } & \text { Multiattribute Value Theory } \\ \text { MAUT: } & \text { Multiattribute Utility Theory } \\ \text { MCDA: } & \text { Multicriteria decision analysis } \\ \text { MCDM: } & \text { Multiple-criteria decision-making } \\ \text { MODM: } & \text { Multiobjective decision-making } \\ \text { NEA: } & \text { Nuclear Energy Agency } \\ \text { NFC: } & \text { Nuclear fuel cycle } \\ \text { NPP: } & \text { Nuclear power plant } \\ \text { PROMETHEE: } & \text { Preference Ranking Organization Method } \\ & \text { for Enrichment Evaluations } \\ \text { SNF: } & \text { Spent nuclear fuel } \\ \text { SSM: } & \text { Simple Scoring Model } \\ \text { TOPSIS: } & \text { Technique for Order Preference by } \\ \text { SAPIERR: } & \text { Similarity to the Ideal Solution } \\ & \text { Support Action: Pilot Initiative for } \\ \text { SPIN: } & \text { European Regional Repositories } \\ \text { tHM: } & \text { The European Project on Safety and } \\ & \text { Performance Indicators } \\ & \text { Tonnes of heavy metal. } \\ & \end{array}$

\section{Disclosure}

A. Schwenk-Ferrero is an NEA German expert and contributed to the NEA Expert Groups: WASTEMAN and Transition Fuel Cycle Scenario Studies launched by the Working Party on Nuclear Fuel Cycle. A. Schwenk-Ferrero and A. Andrianov contribute to the KIND project, as well as IAEA/ INPRO.

\section{Conflicts of Interest}

The authors declare that there are no conflicts of interest regarding the publication of this paper.

\section{Acknowledgments}

The authors would like to acknowledge the international organizations OECD-NEA's expert groups and IAEA's projects whose results were cited in the paper. The authors particularly acknowledge the IAEA/SNF-RAW project MODARIA, in which KIT/IKET participates, EU-funded R\&D project (SPIN coordinated by German Gesellschaft für Anlagen und Reaktorsicherheit (GRS)), and the INPRO/ IAEA section coordinating the KIND/INPRO project on "MCDA Application to Comparative Evaluation of Nuclear Energy Systems.”

\section{References}

[1] International Atomic Energy Agency, Nuclear Technology Review, GC(60)/INF/2, 2016.

[2] International Atomic Energy Agency, Technological Implications of International Safeguards for Geological Disposal of Spent Fuel and Radioactive Waste, Nuclear Energy Series. no. NW-T$1.21,2010$.

[3] IAEA, Policies and Strategies for Radioactive Waste Management, IAEA Nuclear Energy Series no. NW-G-1.1, 2009.

[4] V. Štefula, "Inventory of Radioactive Wastes," Technical report of SAPIERR project, Deliverable D1, 2004.

[5] A. Schwenk-Ferrero, "German spent nuclear fuel legacy: characteristics and high-level waste management issues," Science and Technology of Nuclear Installations, vol. 2013, Article ID 293792, 11 pages, 2013.

[6] OECD, NEA OECD Nuclear Energy Data 7300, OECD, 2016, http://www.oecd-nea.org/ndd/pubs/2016/7300-ned-2016.pdf.

[7] EASAC, "Management of spent nuclear fuel and its waste," JRC Reference Report 23, 2014.

[8] International Atomic Energy Agency, "Technical, economic and institutional aspects of regional spent fuel storage facilities," IAEA TECDOC No 1482, 2005.

[9] International Atomic Energy Agency, Safety Indicators in Different Timeframes for The Safety Assessment of Underground Radioactive Waste Repositories, IAEA-TECDOC-767.

[10] International Atomic Energy Agency, Safety Indicators for The Safety Assessment of Radioactive Waste Disposal, IAEATECDOC-1372.

[11] International Atomic Energy Agency, Radioactive Waste Management Objectives, IAEA Nuclear Energy Series no. NW-O, IAEA, Vienna, Austria, 2011. 
[12] United States Department of Energy, Guidebook to Decision Making Methods, WSRC-IM-2002-00002, USDOE, Washington, DC, USA, 2001.

[13] R. L. Keeney and H. Raiffa, Decision with Multiple Objectives, John Wiley \& Sons, New York, NY, USA, 1976.

[14] C. L. Hwang and K. Yoon, Multiple Attribute Decision Making: Methods and Applications, vol. 186, Springer, Berlin, Germany, 1981.

[15] J.-P. Brans and P. Vincke, "A preference ranking organisation method: (The PROMETHEE method for multiple criteria decision-making)," Management Science, vol. 31, no. 6, pp. 647656, 1985.

[16] T. L. Saaty, The Analytic Hierarchy Process, McGraw-Hill, New York, NY, USA, 1980.

[17] International Atomic Energy Agency, Selection of Away-fromReactor Facilities for Spent Fuel Storage, IAEA TECDOC no. 1558, 2007.

[18] International Atomic Energy Agency, "Agency," A Guidebook on Spent Fuel Storage (IAEA technical series Report) 240, 1991.

[19] "An Integrated Approach to the Back-End of the Fuel Cycle Conference ID: 46528 (CN-226)," in Proceedings of the International Conference on Management of Spent Fuel from Nuclear Power Reactors, vol. 19, Vienna, Austria, June 2015.

[20] "Identifying and Testing Indicators for Assessing The LongTerm Performance of Geological Repositories The European SPIN Project (Project FIKW-CT-2000-00081)," https://cordis .europa.eu/documents/documentlibrary/66628791EN6.pdf.

[21] K. Taji, J. K. Levy, J. Hartmann et al., "Identifying potential repositories for radioactive waste: multiple criteria decision analysis and critical infrastructure systems," International Journal of Critical Infrastructures, vol. 1, no. 4, pp. 404-423, 2005.

[22] A. Andrianov, V. Kanke, I. Kuptsov, and V. Murogov, “Towards sustainable nuclear power development," International Journal for Nuclear Power, vol. 59, no. 5, pp. 287-293, 2014.

[23] T. Briggs, P. L. Kunsch, and B. Mareschal, "Nuclear waste management: An application of the multicriteria PROMETHEE methods," European Journal of Operational Research, vol. 44, no. 1, pp. 1-10, 1990.

[24] L. D. Phillips, "Multi-Attribute Decision Analysis for Recommending Sites to Be Investigated for Their Suitability as a Repository for Radioactive Wastes," Nirex Science Report PE/NRX/18.

[25] J. Figueira, G. Salvatore, and E. Matthias, Multiple Criteria Decision Analysis: State of the Art Surveys, Springer, Boston, Mass, USA, 2005.

[26] V. Belton and T. J. Stewart, Multiple Criteria Decision Analysis: An Integrated Approach, Kluwer Academic Publishers, Dordrecht, the Netherlands, 2002.

[27] D. von Winterfeldt and W. Edwards, Decision Analysis and Behavioral Research, Cambridge University Press, Cambridge, UK, 1986.

[28] V. Kuznetsov, G. Fesenko, A. Schwenk-Ferrero, A. Andrianov, and I. Kuptsov, "Innovative nuclear energy systems: state-of-the art survey on evaluation and aggregation judgment measures applied to performance comparison," Energies, vol. 8, no. 5, pp. 3679-3719, 2015.

[29] V. Kuznetsov, G. Fesenko, A. Andrianov, and I. Kuptsov, "INPRO activities on development of advanced tools to support judgment aggregation for comparative evaluation of nuclear energy systems," Science and Technology of Nuclear Installations, vol. 2015, Article ID 910162, 2015.
[30] R. Steur, F. Depisch, and J. Kupitz, "The Status of the IAEA International Project on Innovative Nuclear Reactors and Fuel Cycles (INPRO) and the Ongoing Activities of the Phase $1 \mathrm{~B}$ of INPRO," in Proceedings of the 12th International Conference on Nuclear Engineering, pp. 377-384, Arlington, Va, USA, April 2004, https://www.iaea.org/INPRO/CPs/index.html.

[31] International Atomic Energy Agency, Nuclear Energy Basic Principles, IAEA Nuclear Energy Series no. NE-BP, IAEA, Vienna, Austria, 2008.

[32] C. Boutellier, C. McCombie, and I. Mele, "Multinational repositories: ethical, legal and political/public aspects," International Journal of Nuclear Law, vol. 1, no. 1, 2006.

[33] R. Wigeland, T. Taiwo, H. Ludewig et al., "Nuclear Fuel Cycle Evaluation and Screening," Final Report, Fuel Cycle Research \& Development FCRD-FCO-2014-000106, Department of Energy (DOE), 2014.

[34] A. Andrianov, V. Kanke, I. Kuptsov, and V. Murogov, "Reexamining the ethics of nuclear technology," Science and Engineering Ethics, pp. 1-20, 2014.

[35] A. A. Andrianov, "Approaches and software for multi-objective optimization of nuclear power structures," Sustainability, vol. 4, no. 4, pp. 721-739, 2012.

[36] A. Andrianov, I. Kuptsov, and T. Utyanskaya, "Application of multi-objective and robust optimization methods for a comparative evaluation of nuclear energy system deployment scenarios," Nuclear Energy and Technology, vol. 2, no. 2, pp. 102107, 2016.

[37] A. Andrianov, Y. Korovin, I. Kuptsov, V. Murogov, and O. Andrianova, "Consideration of economic risks in a comparative analysis of nuclear technologies with different maturity levels," Nuclear Energy and Technology, vol. 3, no. 2, pp. 158-163, 2017.

[38] H. Wang, W. Jiao, R. Lahdelma, C. Zhu, and P. Zou, "Stochastic multicriteria acceptability analysis for evaluation of combined heat and power units," Energies, vol. 8, no. 1, pp. 59-78, 2015.

[39] S. Yoon et al., "An Integrated Multicriteria Decision-Making Approach for Evaluating Nuclear Fuel Cycle Systems for LongTerm Sustainability on the Basis of an Equilibrium Model: Technique for..., Nuclear Engineering and Technology," 2016, http://dx.doi.org/10.1016/j.net.2016.07.009.

[40] J. S. Dyer, J. C. Butler, T. Edmunds, and J. Jia, "A multiattribute utility analysis of alternatives for the disposition of surplus weapons-grade plutonium," Operations Research, vol. 46, no. 6, pp. 749-762, 1998.

[41] R. P. Hämäläinen, M. R. K. Lindstedt, and K. Sinkko, "Multiattribute risk analysis in nuclear emergency management," Risk Analysis, vol. 20, no. 4, pp. 455-467, 2000.

[42] J. C. Butler, A. N. Chebeskov, J. S. Dyer, T. A. Edmunds, J. Jia, and V. I. Oussanov, "The United States and Russia evaluate plutonium disposition options with multiattribute utility theory," Interfaces, vol. 35, no. 1, pp. 88-101, 2005.

[43] W. S. Charlton, R. F. Lebouf, C. Gariazzo et al., "Proliferation resistance assessment methodology for nuclear fuel cycles," Nuclear Technology, vol. 157, no. 2, pp. 143-156, 2007.

[44] S. K. Kim, H. S. Park, and C. H. Jung, "MAUT approach for selecting a proper decommissioning scenario," in Proceedings of the (WM '07) Conference, Tucson, Ariz, USA, February 2007.

[45] K. N. Papamichail and S. French, "25 years of MCDA in nuclear emergency management," IMA Journal of Management Mathematics, vol. 24, no. 4, pp. 481-503, 2013. 


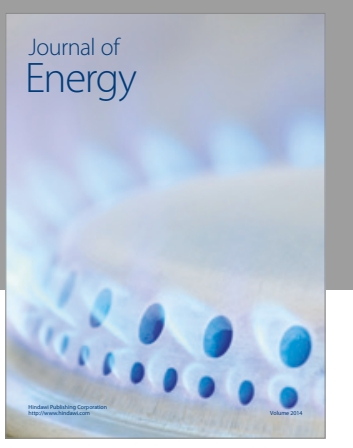

Journal of

Industrial Engineering
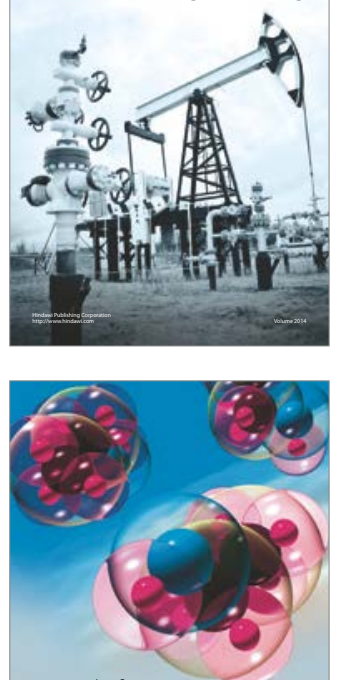

Fuels
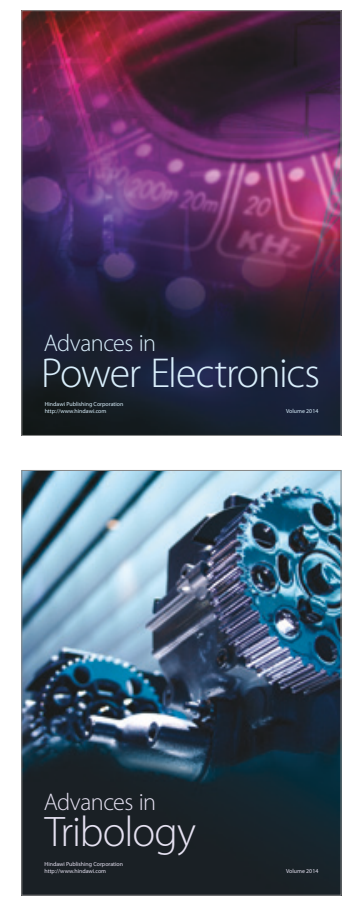
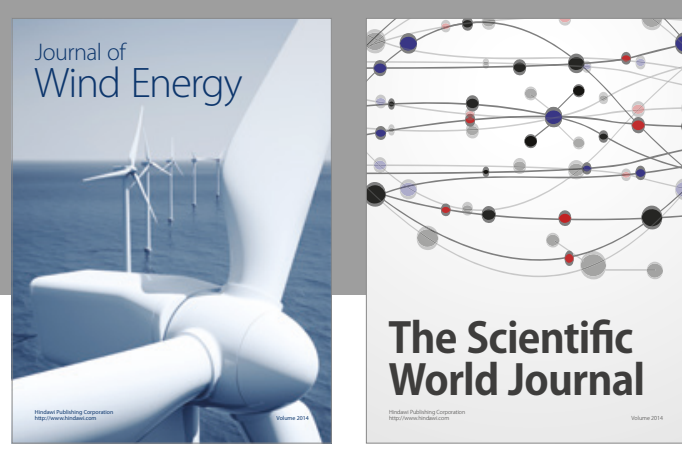

The Scientific World Journal
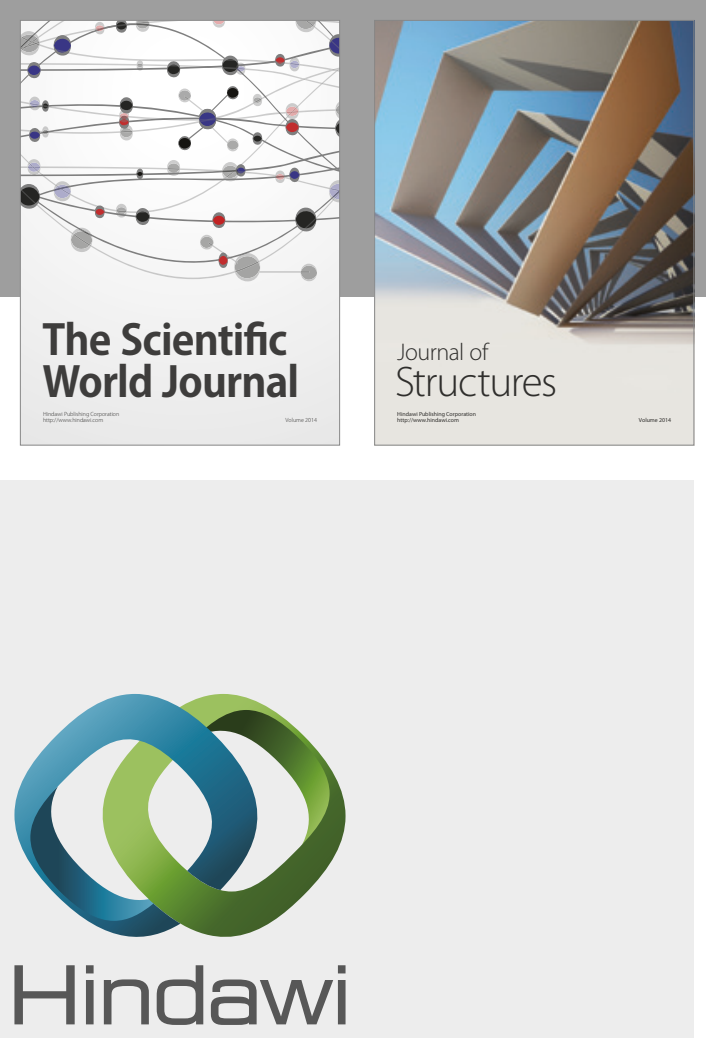

Submit your manuscripts at

https://www.hindawi.com
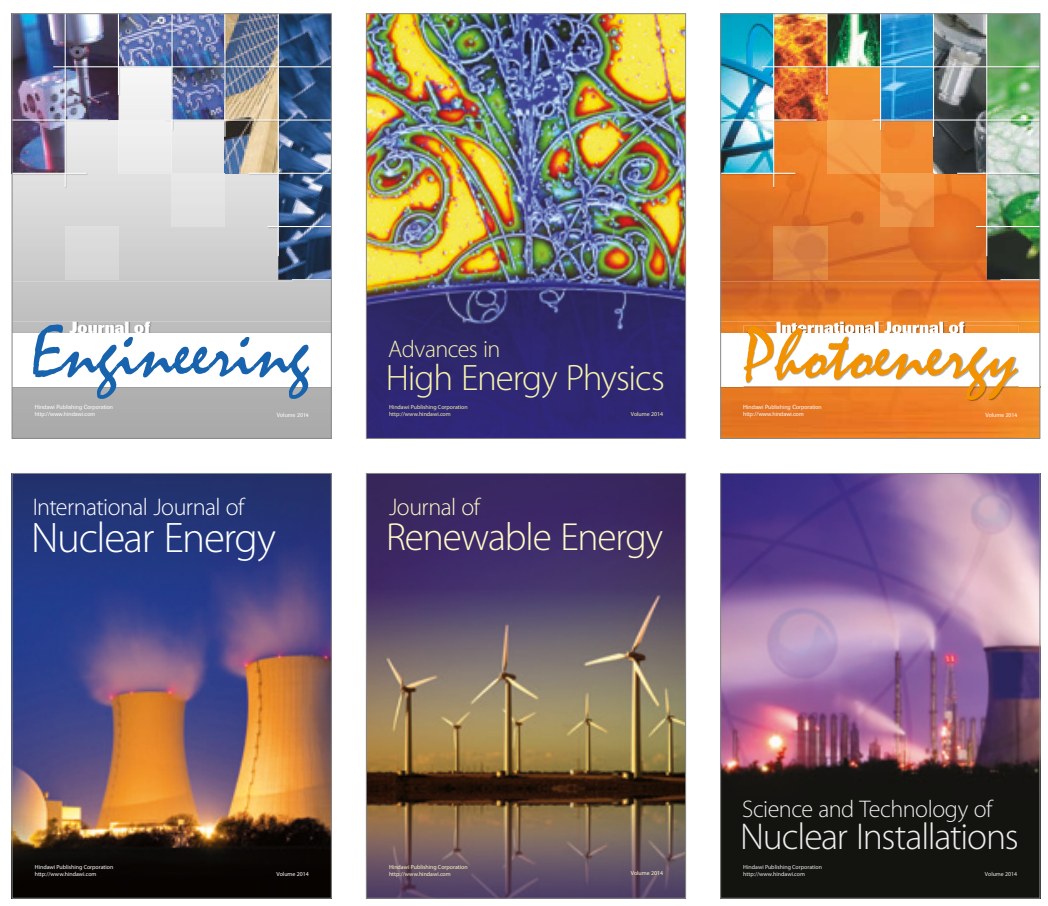

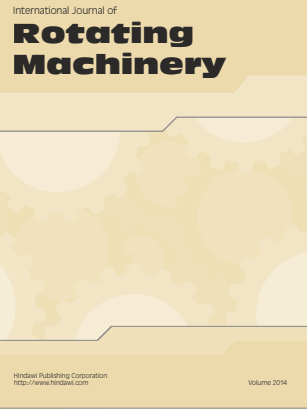

Journal of

Petroleum Engineering

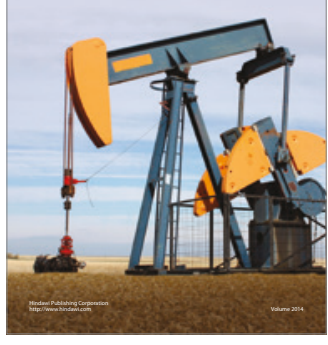

Journal of
Solar Energy
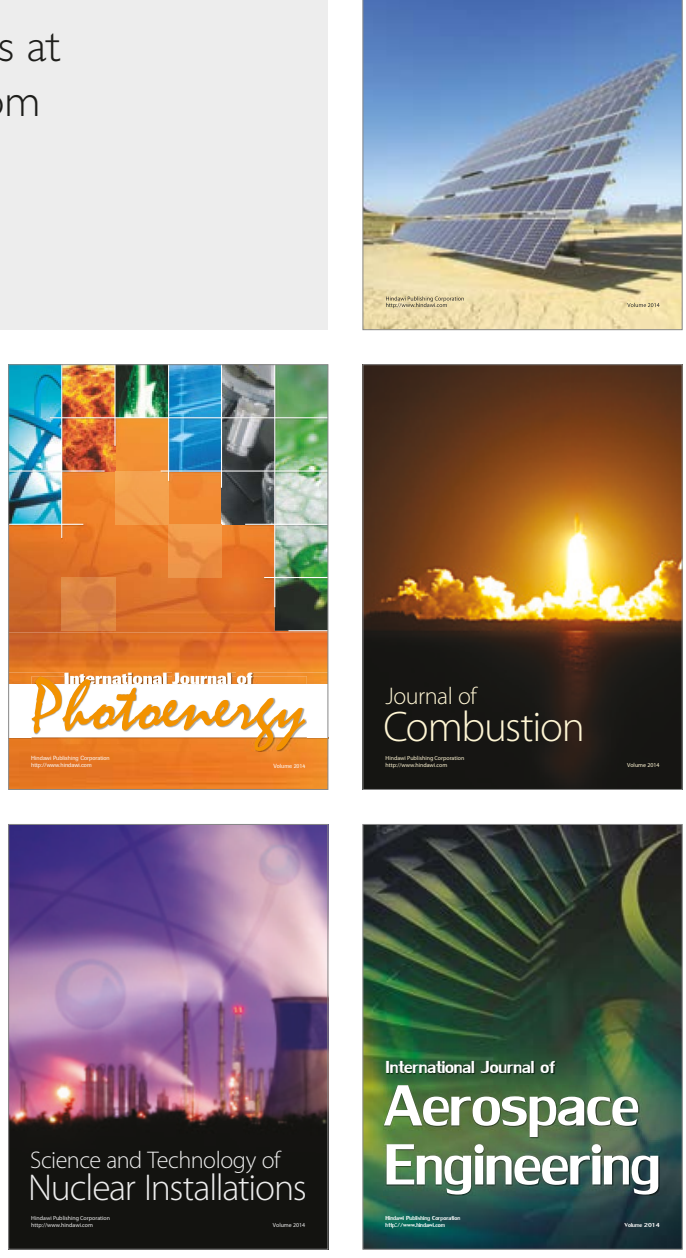